\title{
Corporate Debt Structure and Economic Recoveries
}

Thomas Grjebine, Urszula Szczerbowicz \& Fabien Tripier

\section{Highlights}

- We provide a cross-country study of the business cycle behavior of corporate debt structure for twenty five countries over the period 1989-2013.

- The substitution of bonds for loans, widely described during the Great Recession, is a general pattern of recoveries.

- Economies with high bond share and important bond-loan substitution recover from the recessions faster.

- The interaction between economic recoveries and corporate debt structure is stronger in recessions with banking crisis than in normal récessions.

- A theoretical model is developed to explain how the bond-loan substitution softens the recession costs. 


\section{Abstract}

This paper analyzes the business cycle behavior of the corporate debt structure and its interaction with economic recovery. The debt structure is measured as the share of bonds in the total credit to non-financial corporations for a quarterly panel of twenty five economies over the period 1989-2013. We first show that the substitution of loans for bonds in recoveries is a regular property of business cycles. Secondly, we provide evidence that economies with high bond share and important bond-loan substitution recover from the recessions faster. The relation between the corporate debt structure and the economic recovery is maintained when controls for the developments of financial markets are introduced. A theoretical model is developed to explain this relation as the outcome of financial constraints on bank credit supply.

\section{Keywords}

Corporate Debt, Bonds Markets, Banking, Business Cycles, Recovery, Financial Frictions.

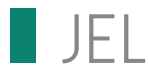

E3, E4, G1, G2.

\section{Working Paper}

\section{CEPII}

CEPII (Centre d'Etudes Prospectives et d'Informations Internationales) is a French institute dedicated to producing independent, policyoriented economic research helpful to understand the international economic environment and challenges in the areas of trade policy, competitiveness, macroeconomics, international finance and growth.
CEPII Working Paper

Contributing to research in international economics

(C) CEPII, PARIS, 2014

All rights reserved. Opinions expressed in this publication are those of the author(s) alone.

$\begin{array}{ll}\text { Editorial Director: } & \text { CEPII } \\ \text { Sébastien Jean } & 113, \text { rue de Grenelle } \\ & 75007 \text { Paris } \\ \text { Production: } & +33153685500 \\ \text { Laure Boivin } & \\ \text { No ISSN: } 1293-2574 & \text { Prw.cepii.fr }\end{array}$




\title{
Corporate Debt Structure and Economic Recoveries ${ }^{1}$
}

\author{
Thomas Grjebine, ${ }^{*}$ Urszula Szczerbowicz ${ }^{\dagger}$ and Fabien Tripier ${ }^{\ddagger}$
}

\section{Introduction}

During the Great Recession of 2008-2009, the total credit to the US non financial corporations declined and the structure of corporate debt shifted from bank debt to market debt. ${ }^{2}$ This time-varying composition of corporate debt has been stressed by Adrian et al. (2012) and Becker and Ivashina (2014) as essential to understand the transmission of the financial crisis to the non financial sector during the Great Recession in the US economy. Indeed, the issuance of market debt helps firms to mitigate the contraction in the supply of bank debt by troubled banks. These findings support policies designed to develop markets for corporate debt securities, capable of replacing impaired bank lending during recessions, to soften the recession costs. ${ }^{3}$ However, besides this recent US experience, business cycle evidence that supports this view is relatively scarce. ${ }^{4}$ This paper fills the gap by providing

\footnotetext{
${ }^{1}$ We thank Adam Gulan, Marlène Isoré, Sébastien Jean, Antti Ripatti, Natacha Valla and seminar participants at Banque de France and at the University of Helsinki HECER Macroeconomic seminar.

${ }^{*}$ CEPII (thomas.grjebine@cepii.fr)

†CEPII (urszula.szczerbowicz@cepii.fr)

‡Univ. Lille 1 - CLERSE \& CEPII (fabien.tripier@univ-lille1.fr)

${ }^{2}$ The decline in total credit illustrates the well-known pro-cyclical behavior of credit which has motivated the inclusion of financial frictions in business cycle literature by Bernanke and Gertler (1989) and Carlstrom and Fuerst (1997). This literature studies how external finance moves with the business cycle but generally considers a single source of debt and therefore can not explain changes in the debt composition.

${ }^{3}$ There exists a large literature on the relative merits of bank-based versus market-based financial systems for the economic development and growth, see Levine (2005) and Herring and Chatusripitak (2007). More recently, the European Commission (2014) claims that "Policy effort is needed in Europe to diversify financing channels. European capital markets are on average relatively underdeveloped and are currently insufficient to fill the funding gap created by bank deleveraging".

${ }^{4}$ See De Fiore and Uhlig (2012) and Rodriguez-Palenzuela et al. (2013) for the Euro area economy during the 2008-2009 Great recession. Becker and Ivashina (2014) compare the growth rates of market and bank debts at the aggregate level since 1953 but only for the US economy. Crouzet (2014) show the differences between the corporate debt structure between small and large firms during the US Great Recession. Allard and Blavy (2011) study the impact of financial structures on business cycles by comparing recoveries in market-based and bank-based economies. However, they do not take into account variations across time of the financial structures and include equity markets in the market sources of finance whereas we focus here on corporate debt.
} 
a cross-country study of the business cycle behavior of corporate debt structure. First, we analyze the variations of the corporate debt structure around recessions and find that the firms substitute bank debt by market debt in recoveries. Second, we investigate whether the access to corporate bond finance matters in the aftermath of recessions. We show that the economies with higher share of corporate debt and large substitution from loans to bonds experience shorter and more vigorous recoveries. ${ }^{5}$

Our main measure of the corporate debt structure is the ratio of the amount of bonds issued by non-financial corporations to the total credit provided to them, referred to as "bond share" in the remainder. We use two BIS databases to construct this ratio: the total debt securities issued by non-financial corporations and the total credit provided to the non-financial corporations. We use the first series to measure the "bond" financing in the economy, also referred to as market debt in the remainder, and the second to measure the rest of credit which is called "loan", also referred as bank debt in the remainder. Our quarterly panel for corporate debt structure covers twenty five advanced and emerging economies since 1989 for most countries. The bond share ratio is reminiscent of the financing mix between bank loans and commercial papers proposed by Kashyap et al. (1993) to identify credit supply shocks in the bank lending literature. ${ }^{6}$

Business cycles are defined by using the methodology of cyclical turning points developed by Bry and Boschan (1971) and Harding and Pagan (2002). Traditionally, a business cycle is divided into two phases: the recession, between the peak and the subsequent trough, and the expansion, between the trough and the subsequent peak - see Burns and Mitchell (1946). However, there is a growing interest in the literature for another phase of the cycle: the recovery which is the period between the trough and when the economy recovers the level of activity that occurred before the recession - see among others Bordo and Haubrich (2012) and Fatás and Mihov (2013).

We identify the peaks of real GDP for each country and study the behavior of corporate

\footnotetext{
If the theoretical part of the paper proposes a causal explanation of this fact (based on the financial constraints on bank credit supply), it should be emphasized that our empirical results establish correlation and not causation between corporate debt structure and economic recovery.

${ }^{6}$ This work has initiated controversies on the relevance of the Kashyap et al. (1993)'s methodology to identify credit supply shocks. Oliner and Rudebusch (1996) claim that it is a difference between small and large firms that drives the Kashyap et al. (1993)'s evidence. However, the existence of the bank lending channel has been confirmed with detailed micro-data by Becker and Ivashina (2014). Moreover, during the Great Recession credit standards tightened in the Euro area and the US not only for small firms but also for large ones, see the ECB Bank Lending Survey and Senior Loan Officer Opinion Survey on bank lending practices.
} 
debt around these peaks. The substitution of bonds for loans, widely described after the Great Recession, is robustly observed in other recoveries of our panel. More precisely, the substitution starts one year after the peak when the economy exits from the recession and enters in the recovery phase. We then test whether important access to bond finance is associated with milder recessions and stronger recoveries. While we find no significant link for the recession phase, the recoveries are related to the country's access to bond financing. The high level of bond share before recession and the large bond share increase after the peak are associated with more vigorous and faster recoveries. ${ }^{7}$

Our results complement the large empirical literature on the interactions between financial markets and business cycles - see the influential contributions of Bordo et al. (2001) and Schularick and Taylor (2012). In particular, Claessens et al. (2012) and Jordà et al. (2013) show how the costs of recessions are amplified by the development of financial markets before peaks. We reach a similar conclusion for our panel of recessions when we include the series of excess credit growth and housing prices as suggested by Claessens et al. (2012) and Jordà et al. (2013). The link identified between the corporate debt structure and recoveries may be a by-product of financial booms, which could modify the composition of corporate debt before recession. To show the existence of a specific effect of corporate debt structure, the series of financial market developments are introduced as controls in our benchmark regressions. We also control for the structural differences between economies using country fixed effects and measures of firm size distribution.

A natural explanation of the role of corporate debt in business cycles is that bond financing replaces impaired bank lending during recoveries and therefore stimulates total credit, investment, and output growth. The role of credit in recoveries is however controversial since Calvo et al. (2006) pointed out the existence of credit-less recoveries, or "phoenix miracles", that is recovery of output without recovery of credit. Actually, we show that the relationship between credit and output growth is affected by the structure of corporate debt. The correlation between total credit and output is stronger in economies where the share of bond in corporate debt is high. ${ }^{8}$

In the last section, we provide a theoretical explanation of these empirical results. In the

\footnotetext{
${ }^{7}$ This finding suggests a potential benefit of market-based finance when compared with bank-based finance in the aftermath of recessions. A full assessment of the relative merits and disadvantages of these two financial systems should naturally include other dimensions of welfare such as economic growth and stability. ${ }^{8}$ This conclusion holds whether the credit is specified as a stock variable, as in Calvo et al. (2006), or as a flow variable as in Biggs et al. (2010) and Abiad et al. (2011). See Coricelli and Roland (2011) for a discussion of the two specifications.
} 
theoretical literature on the composition of corporate debt, banks are monitoring firms which can alleviate the problem of asymmetric information but at costs that make bank finance more expensive than bond finance. Firms with good characteristics have access to the cheaper market debt because the agency issue is less severe for firms with good reputation in Diamond (1991) or high level of publicly observable capital in Holmstrom and Tirole (1997). ${ }^{9}$ Rodriguez-Palenzuela et al. (2013) emphasize the limits of the literature to explain the shift form bank debt to bond debt during the Great Recession. Because an economic crisis deteriorates the fundamentals of firms, for example their net worth, fewer firms should have access to the bond market leading to a shift from market debt to bank debt during bad times and not the opposite. Adrian et al. (2012) and De Fiore and Uhlig (2012) are two recent theoretical contributions that solve this puzzling behavior of corporate debt structure - see also Crouzet (2014) who develops a model where firms use multiple types of debt instruments simultaneously. De Fiore and Uhlig (2012) assume an increase in the information acquisition costs of banks that makes indirect finance more expansive and leads some firms to exit from the banking sector either to abandon production or to be directly financed. In Adrian et al. (2012), it is the leverage of banks that plays a key role in the time-varying composition of corporate debt. The credit supply by banks diminishes during a recession because they have to reduce their exposition to the rising risk of default given a Value-at-Risk constraint. We extend this model by considering the banks' financial losses during the recession, which limit the bank credit supply during recovery. Numerical simulations of the model show that bond share increases not only in recessions, as in Adrian et al. (2012), but also in recoveries due to financial losses. The recovery is slower in a bank-based economy than in a market-based economy.

The remainder is as follows. Section 2 presents the data and provides an international comparison of corporate debt structure. Section 3 describes the business cycle behavior of the corporate debt structure and the substitution process between debt instruments. Section 4 shows the interaction between the corporate debt structure and the recovery. Section 5 is devoted to the theoretical model and Section 6 concludes.

\section{Data}

This section presents the data and shows the main cross-country differences in corporate debt structures.

A primary challenge is to define a unified variable that represents the corporate debt

\footnotetext{
${ }^{9}$ See Freixas and Rochet (2010) for a survey of the microeconomic literature, De Fiore and Uhlig (2011) for an extension of in general equilibrium.
} 
structure for several countries over long periods of time. We use two databases published by the BIS to decompose the total credit into loans and bonds. The first database entitled Long series on credit to private non-financial sectors provides a measure of the total credit distributed to the non-financial corporations in nominal terms at the quarterly frequency for a large set of countries over the last decades. The definition of total credit used by the BIS is large and encompasses the credit provided by domestic banks and all other sectors of the economy including the non-residents. ${ }^{10}$ This series is referred to as "total credit" in the remainder of the paper. Unfortunately, this database does not allow the breakdown between loans and debt securities of non financial corporations. ${ }^{11}$ In order to isolate the share of debt securities in total credit we use a second BIS database entitled Debt securities statistics. The series Total debt securities by residence of issuer give the amount of debt securities denominated in US dollars issued by non-financial corporations. We use the nominal exchange rate to convert this series in national currency. This series is referred to as "bond" (also called "market debt") and the "loan" (also called "bank debt") series are computed as the difference between "total credit" and "bond" when both series are available ${ }^{12}$ The series "bond share", defined as the ratio of bond to total credit, characterize the corporate debt structure. Additional information about variables sources can be found in Appendix D.

The final panel encompasses a set of 25 emerging and advanced countries. ${ }^{13}$ The panel starts in 1951Q1 for the United-States, in 1989Q1 for ten countries and ends in 2013Q4 for most countries. As the sample starts much earlier for the Unites-States (in 1951), we check that our results are robust to the exclusion of this country from the panel. Table A.1 reports descriptive statistics for bond share series. On average, debt securities amount to $17 \%$ of the total credit of non-financial corporations over the whole period covered. The bond share has been the highest in the United States: with a mean value of 56\% and a well developed corporate bond market since the 1950s, the United States is clearly

\footnotetext{
${ }^{10}$ In terms of financial instruments, the total credit covers debt securities and loans. It does not include other financing sources, such as trade credit or financial derivatives.

${ }^{11}$ The breakdown is only possible for the whole private non-financial sector and allows separating domestic bank lending from the total credit.

${ }^{12}$ For the US, we use the long series from the Financial accounts of the United States (see Table D.17 for details). For European countries, loan data from Eurostat start only in 1999. So we do not use this series. We show however in Figures D.7 that our loan variable is identical to Eurostat bank loans to non-financial corporations.

${ }^{13}$ Australia, Austria, Belgium, Canada, China, Czech-Republic, Denmark, Finland, France, Germany, HongKong, Hungary, Ireland, Italy, Japan, Luxembourg, the Netherlands, Norway, Portugal, Singapore, Spain, Sweden, Thailand, the United-Kingdom, and the United States.
} 
a special case. The second country to rely significantly on bond finance is Singapore, with a mean value of $40 \%$, followed by the United Kingdom, with mean value of $22 \%$. For the 21 other countries, the bond share is on average below $20 \%$ with the smallest values (below 5\%) in Ireland, Hungary, Sweden, and Spain.

\section{Substitution Between Loans and Bonds over the Business Cycle}

This section describes the substitution process between bonds and loans and shows that this process is a regular feature of a business cycle. To show how the corporate debt structure varies over the business cycle, we first define the turning points of business cycles for each country in our panel and then characterize the behavior of corporate debts around these points.

We apply the algorithm of Harding and Pagan (2002) ${ }^{14}$ to identify local maxima (peaks) and minima (troughs) in the log-levels of real GDP in each country of our panel. A cycle is composed of two phases: the recession (or contraction) phase starts after a peak and ends at the trough which initiates the expansion phase up to the next peak. The parameters of the algorithm are fixed such that a full cycle and each of its phase must last at least 4 quarters and 2 quarters, respectively. We do not consider the full expansion phases because of our interest for business cycle properties rather than for long-run growth. ${ }^{15}$ Instead, we consider the recovery phase that is the period between the trough and when the economy recovers the level of activity that occurred before the recession. Table A.2 reports the basic features of the business cycles in our panel. We identify 93 recessions and 89 recoveries. A recession lasts on average 4.32 quarters and results in a median output decline of $2.09 \%$ (so called amplitude of a recession). A typical recovery takes 3.84 quarters and is followed by a median output increase of $2.38 \%$. Therefore, in the reminder of the paper, we focus on the years after peaks and interpret the first year as a recession and the second year as a recovery.

To characterize the business cycle behavior of corporate debts, we define $\hat{x}_{t, k, i}=x_{t, k, i} / x_{0, k, i}$ as the deviation of series $x$ with respect to its value at the peak (the peak date is normalized to 0$)$ for $t \in[-8: 8]$ quarters before or after the peak in country $i(k=1, \ldots, K$ indexes recessions). To assess the robustness of our results, the growth rates of series are also considered $g_{x, t, k, i}^{j}=\log \left(x_{t, k, i} / x_{t-j, k, i}\right)$ where $g_{x, t, k, i}^{j}$ is the quarterly growth rate of $x$ for

\footnotetext{
${ }^{14}$ This algorithm constitutes a quarterly implementation of the original algorithm of Bry and Boschan (1971) for monthly series.

${ }^{15}$ Actually, expansion phases are much more longer than recession phases and during expansion the economy follows its long-run trend of economic growth.
} 
Figure 1 - GDP, Bonds and Loans over the cycle
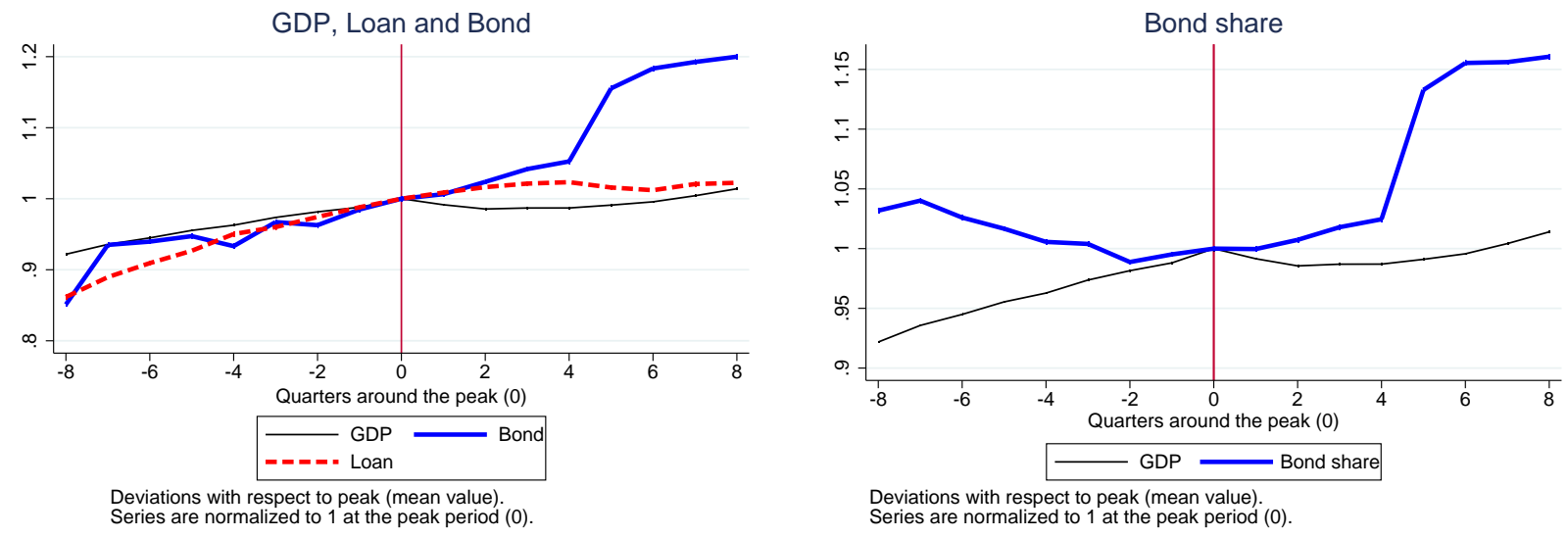

Figure 2 - GDP, Bonds and Loans in the US Great Recession
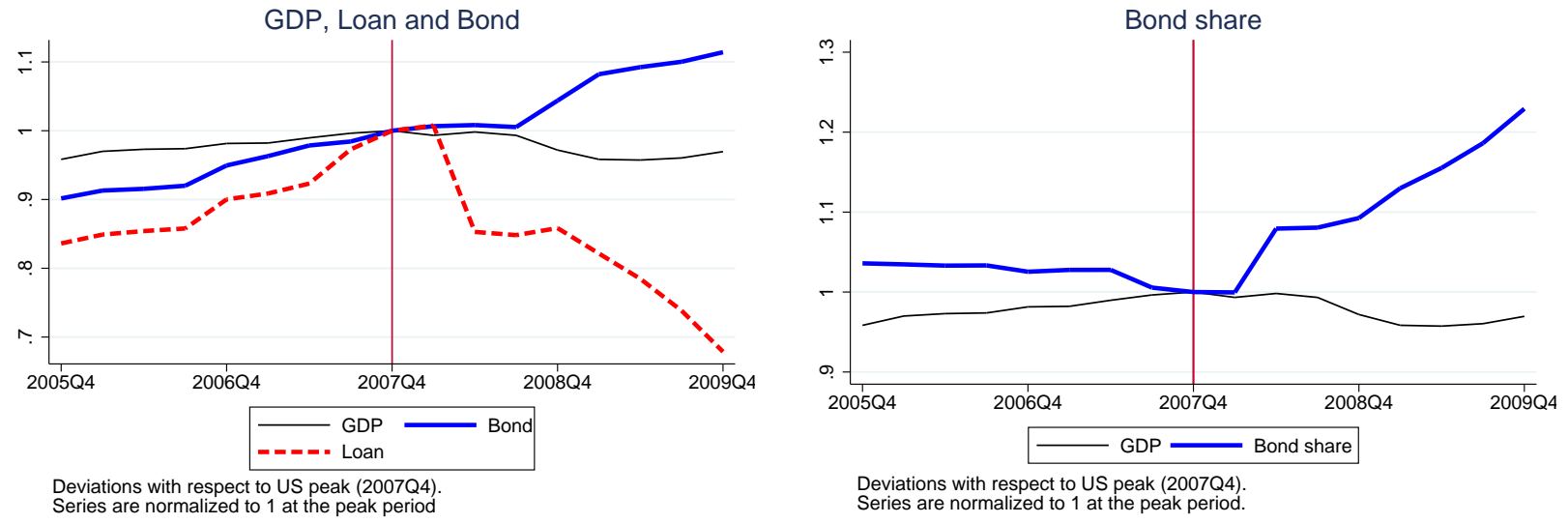

$j=1$ and its year-to-year growth rate for $j=4$. We first comment graphically the evolution of series and then employ regression analysis to verify statistical significance of the exhibited patterns.

The left panel of Figure 1 depicts the average deviations of real GDP, bonds and loans for all the peaks of our sample. The growth of real GDP in the expansion phase stops at the peak and then becomes negative during four quarters. Eight quarters after the peak, the economy recovers: the level of real GDP reaches its value of the previous peak. The growth of real bonds and real loans are on average positive before and after the peaks. It is worth mentioning however that series are not detrended. Therefore the slow growth of loans after the peak could also be interpreted as a credit crunch: the cumulative growth of loans is close to $1 \%$ during the two years after the peak against a cumulative growth of $13 \%$ during the two years before the peak. It is the opposite for the growth of bonds: the cumulative growth of bond reaches $20 \%$ during the two years after the peak against 
Table 1 - Bond, Loan and Bond Share over Business cycles

\begin{tabular}{lccc|ccc}
\hline \hline & $\begin{array}{c}(1) \\
\text { Bond share } \\
(\text { OLS })\end{array}$ & $\begin{array}{c}(2) \\
\text { Loan } \\
(\text { OLS })\end{array}$ & $\begin{array}{c}(3) \\
\text { Bond } \\
(\text { OLS })\end{array}$ & $\begin{array}{c}(4) \\
\text { Bond share(gr.) } \\
(\text { OLS })\end{array}$ & $\begin{array}{c}(5) \\
\text { Loan(gr.) } \\
(\text { OLS })\end{array}$ & $\begin{array}{c}(6) \\
\text { Bond(gr.) } \\
(\text { OLS })\end{array}$ \\
\hline$Y_{1}$ & 0.0125 & $0.0169^{*}$ & 0.0314 & 0.000305 & -0.00354 & -0.00956 \\
& $(0.0513)$ & $(0.00979)$ & $(0.0533)$ & $(0.0152)$ & $(0.00489)$ & $(0.0149)$ \\
$Y_{2}$ & $0.145^{* * *}$ & $0.0165^{*}$ & $0.176^{* * *}$ & $0.0655^{* * *}$ & $-0.0439^{* * *}$ & $0.0321^{* *}$ \\
& $(0.0525)$ & $(0.01000)$ & $(0.0546)$ & $(0.0159)$ & $(0.00513)$ & $(0.0156)$ \\
$Y_{-1}$ & 0.0240 & $0.0364^{* * *}$ & 0.0501 & 0.000305 & -0.00354 & -0.00956 \\
& $(0.0530)$ & $(0.0101)$ & $(0.0549)$ & $(0.0168)$ & $(0.00544)$ & $(0.0165)$ \\
$Y_{-2}$ & -0.0223 & $0.114^{* * *}$ & 0.0616 & $-0.0358^{*}$ & $0.0174 * * *$ & -0.0290 \\
& $(0.0556)$ & $(0.0106)$ & $(0.0577)$ & $(0.0195)$ & $(0.00620)$ & $(0.0192)$ \\
\hline Observations & 1,079 & 1,095 & 1,072 & 1,834 & 2,145 & 1,884 \\
$R^{2}$ & 0.084 & 0.289 & 0.089 & 0.101 & 0.126 & 0.121 \\
\hline
\end{tabular}

Standard errors in parentheses. $* * * \mathrm{p}<0.01, * * \mathrm{p}<0.05, * \mathrm{p}<0.1$. Country fixed effects included

"Bond share", "Loan" and "Bond" are calculated with respect to GDP peak. "Bond share(gr.)", "Loan(gr.)" and "Bond(gr.)" are in annual growth terms (d04LN). $Y_{1}$ corresponds to one year after the peak.

a cumulative growth of $13 \%$ during the two years before the peak. The loan and bond deviations follow a similar pattern in the two years before peaks but diverge strongly in the aftermath of recessions. The bond share depicted in the right panel of Figure 1 shows that the shift in the corporate debt structure occurs during the second year after peaks with a final increase of about 15\%. Figure 2 shows the same data for the Great Recession in the United States. This recession has been exceptionally severe. Two years after the peak the real GDP has still not recovered its value of 2007Q4, and the fall in loans was particularly drastic (above 30\%). Despite these differences, the bond-loan substitution during this recession led to $20 \%$ increase in the bond share, close to the $15 \%$ increase observed on average in our panel.

To test the statistical significance of the bond-loan substitution after peaks, we regress the series $\hat{x}_{t, k, i}$ on dummy variables $Y_{j}$, which are equal to one when $t$ belongs to the year $j$ for the $j=[-2 ;-1 ;+1 ;+2]$ years before or after the peak. ${ }^{16}$ To measure to what extent the behavior of the corporate debt structure varies with business cycle phases, the following

\footnotetext{
${ }^{16}$ For example, $Y_{1}=1$ when $t=[1,2,3,4]$. We group quarterly observations within year variables. In Section 4.4, we show that our results are robust at a quarterly frequency.
} 
regression is estimated:

$$
\hat{x}_{t, k, i}=\sum_{j=-2, j \neq 0}^{j=2} \delta_{j} \times Y_{j}+\bar{a}+a_{i}+\epsilon_{t, k, i}
$$

where $i=1, \ldots, N$ indexes countries, $k=1, \ldots, K$ indexes recessions and $j=-2, \ldots, 2$ indexes years around peaks. $\bar{a}$ is the constant and $a_{i}$ are time-invariant country fixed effects.

The columns (1)-(3) of Table 1 report the regression coefficients $\delta_{j}$ for the series of bond share, loan, and bond. To check the robustness of our results, the columns (4)-(6) of Table 1 report the regression coefficients using the growth rate of series $g_{x, t, k, i}^{4}$ instead of the deviation with respect to the peak value $\hat{x}_{t, k, i}$. During the second year after the peak (namely $Y_{2}$ ), the bond share is significantly higher (at the $1 \%$ level of significance) either in deviation or in growth rate, while other dummies are not significant - except for $Y_{-2}$ in column (4) at the $10 \%$ level of significance. Similar results are obtained for the bond series which also increases significantly in $Y_{2}$ (columns (3) and (6)). The loans on the other hand grow much more slowly after peaks. Their variation with respect to peak is still positive but smaller and less significant (only at the $10 \%$ level, column (2)) while the yearly growth rate becomes negative (in $Y_{2}$ at the $1 \%$ level of significance, column (5)). Before peaks, and contrary to the two other series, the loans increase significantly both in term of deviation $\left(Y_{-2}\right.$ and $\left.Y_{-1}\right)$ and in terms of the yearly growth rate $\left(Y_{-2}\right)$. The recessions are thus preceded by booms in the credit supplied by banks. This conclusion is in line with the literature on credit booms and recessions, e.g. Schularick and Taylor (2012).

\section{Substitution Between Loans and Bonds and Economic Recovery}

Having established differences in the business cycle behavior of loans and bonds, we are now interested in the existence of links between the corporate debt structure and the GDP growth after peaks. To test whether the corporate debt structure matters for the shape of business cycle, we estimate the following regression:

$$
\log \left(\hat{y}_{t, k, i}\right)=\beta_{j} \times \log \left(s_{t, k, i}\right)+\Gamma_{j} \times X_{t, k, i}+\epsilon_{t, k, i}
$$

where $i=1, \ldots, N$ indexes countries, $k=1, \ldots, K$ indexes recessions and $t=1, \ldots, 8$ indexes quarters after peaks. $X_{t, k, i}$ includes the constant, time-invariant country fixed effects, and a set of controls introduced in section 4.2. For each recession $k, \hat{y}_{t, k, i}$ is the 
deviation of real GDP with respect to the peak value $t$ quarters after the peak in country $i$ and $s_{t, k, i}$ is the contemporary value of bond share. Estimated coefficients for $\beta_{j}$ and $\Gamma_{j}$ depend on the phase $j$ of the business cycle. Equation (2) is estimated separately for two periods: $j=1$ corresponds to the first year after the peak, namely $Y_{1}$ for $t \in[1,4]$ and $j=2$ to the second year after the peak, namely $Y_{2}$ for $t \in[5,8]$.

\subsection{Corporate Debt Structure and Economic Recovery}

The columns (1) and (2) of Table 2 report the value of the coefficient of interest, $\beta_{j}$, for the first and the second year after the peak (respectively: $Y_{1}$ for $t \in[1,4]$ and $Y_{2}$ for $t \in[5,8])$. Given the duration of business cycle phases established in Section 3 , $Y_{1}$ corresponds to the recession phase and $Y_{2}$ to the recovery phase. The results differ with the business cycle phase considered. The value of bond share is not significantly correlated with the GDP growth during the first year but the correlation becomes positive and significant (at the 1\% level of significance) during the second year. The elasticity of the real GDP deviation with respect to bond share is of about $2 \%$, which is sizable since the average real GDP deviation eight quarters after peaks range between $-2 \%$ and $4 \%-$ see Figure 3.

We find that the real GDP deviation and bond share are positively correlated during recoveries. The contemporary value of the bond share can be further expressed as the outcome of two factors: the initial value of bond share at the date of the peak and its variation between the peak and the recovery phase. The role of the initial value of bond share is especially important because it characterizes the financial structure of the economy before the peak. The bond-loan substitution after the peak is also a relevant corporate debt structure characteristic. To identify the respective role of the initial bond share and the bond-loans substitution, the contemporary bond share series is decomposed as follows:

$$
\log \left(s_{t, k, i}\right)=\log \left(s_{0, k, i}\right)+\log \left(\frac{s_{t, k, i}}{s_{0, k, i}}\right)=\log \left(s_{0, k, i}\right)+\sum_{\tau=0}^{t} g_{s, \tau, k, i}^{1}
$$

By construction, the value of bond share (taken in log) at time $t$ is equal to its value at the peak $s_{0, k, i}$ plus the sum of its quarterly growth rates $g_{s, \tau, k, i}^{1}$ between periods $\tau=0$ and $\tau=t$. Therefore, the equation (2) is re-estimated using the decomposition of bond share series as suggested by the equation (3):

$$
\log \left(\hat{y}_{t, k, i}\right)=\beta_{j}^{1} \times \log \left(s_{0, k, i}\right)+\beta_{j}^{2} \times\left(\sum_{\tau=0}^{t} g_{s, \tau, k, i}^{1}\right)+\Gamma_{j} \times X_{t, k, i}+\epsilon_{t, k, i}
$$

The columns (3) and (4) of Table 2 report the estimated values of $\beta_{j}^{1}$ and $\beta_{j}^{2}$. The two bond share variables are significant at the $1 \%$ level of significance in the second year. The 
increase of real GDP with respect to its peak value during the recovery is stronger when both the value of bond share at the peak and its increase after the peak are the higher.

Table 2 - Corporate debt structure and GDP

\begin{tabular}{|c|c|c|c|c|c|c|c|c|}
\hline & (1) & (2) & (3) & (4) & (5) & (6) & (7) & (8) \\
\hline & GDP & GDP & GDP & GDP & GDP & GDP & GDP & GDP \\
\hline & (OLS) & (OLS) & (OLS) & (OLS) & (OLS) & (OLS) & (OLS) & (OLS) \\
\hline \multirow[t]{2}{*}{ BS } & -0.000657 & $0.0219 * * *$ & & & & & & \\
\hline & $(0.00189)$ & $(0.00424)$ & & & & & & \\
\hline \multirow[t]{2}{*}{$\mathrm{BS}[0]$} & & & -0.00138 & $0.0188 * * *$ & -0.00134 & $0.0157^{* * *}$ & & \\
\hline & & & $(0.00192)$ & $(0.00430)$ & $(0.00189)$ & $(0.00443)$ & & \\
\hline \multirow[t]{2}{*}{$\mathrm{BS}(\mathrm{gr} .0)$} & & & $0.0202 *$ & $0.0243^{* * *}$ & & & $0.0201^{*}$ & 0.0108 \\
\hline & & & $(0.0106)$ & $(0.00818)$ & & & $(0.0107)$ & $(0.00742)$ \\
\hline Obs. & 323 & 273 & 319 & 260 & 319 & 260 & 319 & 260 \\
\hline$R^{2}$ & 0.219 & 0.446 & 0.148 & 0.468 & 0.137 & 0.453 & 0.146 & 0.418 \\
\hline Period & $Y_{1}$ & $Y_{2}$ & $Y_{1}$ & $Y_{2}$ & $Y_{1}$ & $Y_{2}$ & $Y_{1}$ & $Y_{2}$ \\
\hline $\begin{array}{l}\text { Robust st } \\
\text { is calcula } \\
\text { means bo } \\
\text { respect to }\end{array}$ & $\begin{array}{l}\text { andard errors } \\
\text { ted with resp } \\
\text { nd share. "B } \\
\text { the peak per }\end{array}$ & $\begin{array}{l}\text { in parenthes } \\
\text { ect to its lev } \\
\mathrm{S}[0] \text { " is bon } \\
\text { riod. }\end{array}$ & $\begin{array}{l}\text { S. } * * * p<0 \\
\text { lat the pe } \\
\text { share level }\end{array}$ & $\begin{array}{l}01,{ }^{* *} \mathrm{p}<0.0 \\
\mathrm{k} \text { period. } Y_{1} \\
\text { at the peak }\end{array}$ & $\begin{array}{l}5, * p<0.1 \text {. } \\
\text { corresponds } \\
\text { period. "BS }\end{array}$ & $\begin{array}{l}\text { Country fixed } \\
\text { to one year } \\
(\mathrm{gr} .0) " \text { is bor }\end{array}$ & $\begin{array}{l}\text { effects inclu } \\
\text { d ster the pe } \\
\text { sar }\end{array}$ & $\begin{array}{l}\text { ded. GDP } \\
\text { ak. "BS" } \\
\text { ation with }\end{array}$ \\
\hline
\end{tabular}

In columns (5)-(8) of Table 2, the equation 4 is re-estimated with initial bond share and bond share variation separately. We find, on the one hand, the positive link between GDP deviation in the second year after the peak and the value of bond share at the peak, see columns (5) - (6). On the other hand, the columns (7)-(8) show that the bond share variation alone is weakly correlated with the GDP deviations (only in $Y_{1}$ at the $10 \%$ level of significance). However, this correlation becomes strongly significant after controlling for the initial bond share, see columns (3) and (4). Actually, the bond share variation explains the part of the GDP deviation that is not accounted for by the initial bond share. The interpretation of columns (4) and (8) is that the link between the bond-loan substitution and GDP dynamics depends on the inclusion of the initial share of bonds in the corporate debt structure. It is quite intuitive to consider that a $10 \%$ increase in bond share per se does not have the same macroeconomic consequences if bonds represent initially $1 \%$ or $15 \%$ of the debt of non financial corporations.

Figure 3 summarizes the links established by our regressions between the corporate debt structure and real GDP growth. It depicts the deviation of real GDP with respect to the peak value three years after the peak for all the recessions of the panel (see the dashed line), for recessions where the initial value of bond share is high (that is above the mean, see the solid line) and for recessions where the initial value of bond share is low (that is below 
Figure 3 - Recoveries depending on financial structures

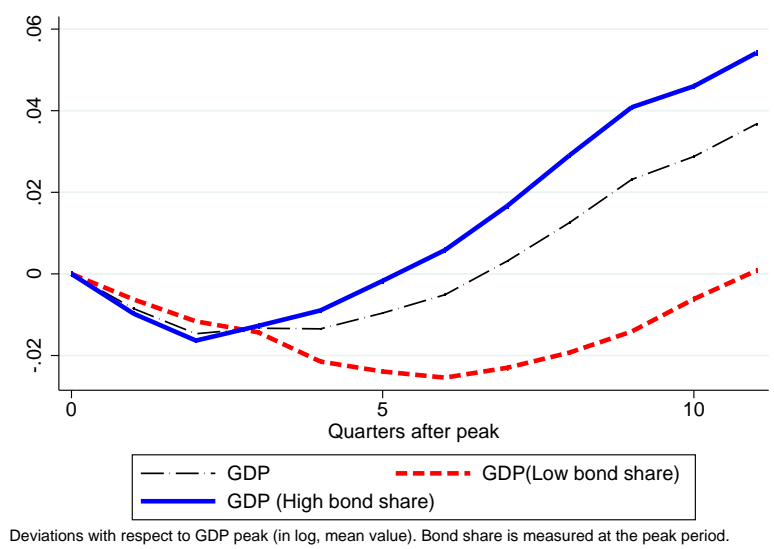

the mean, see the dotted line). Accordingly with our estimation results, no differences are observed during the beginning of the recession: the three lines are very close during the three first quarters. The blue and red lines diverge afterwards. The expansion phase starts on average three quarters after the peak in economies with high bond share against six quarters in economies with low bond share. The gap is even stronger for the recovery. The economies with low bond share recover eleven quarters after the peak while, at this date, the real GDP in economies with low bond share is about 5\% above its peak value. Indeed, the recovery in economies with high bond share occurs earlier, i.e. five quarters after the peak.

\subsection{Controlling for Financial Market Developments}

We are not the first to highlight the interactions between financial markets and the strength of the recovery. Claessens et al. (2012) and Jordà et al. (2013) are two recent influential contributions that put forward the association of financial markets developments with slower recoveries using different datasets - a long-run dataset for advanced countries in Jordà et al. (2013) and a postwar dataset for advanced and emerging countries in Claessens et al. (2012). Our results for the structure of corporate debt could be a by-product of financial market developments omitted in our previous analysis.

Therefore, we include financial market variables in our regressions to verify the existence of a specific relation between the structure of corporate debt and the GDP growth in recoveries. A first set of variables controls for the development of total credit without making the distinction between loans and bonds. It consists of the growth of private credit (of both households and non-financial corporations) after the peak, the ratio of total private credit to GDP at the peak and, following Jordà et al. (2013), the rate of change 
of this ratio, in deviation from its mean, one year before the peak. Furthermore, Claessens et al. (2012) show that equity and housing markets also interact with the business cycles. Accordingly, we include in our regression the stock market capitalization and house prices level at the peak as well as the year-to-year growth rate of house prices after the peak. 


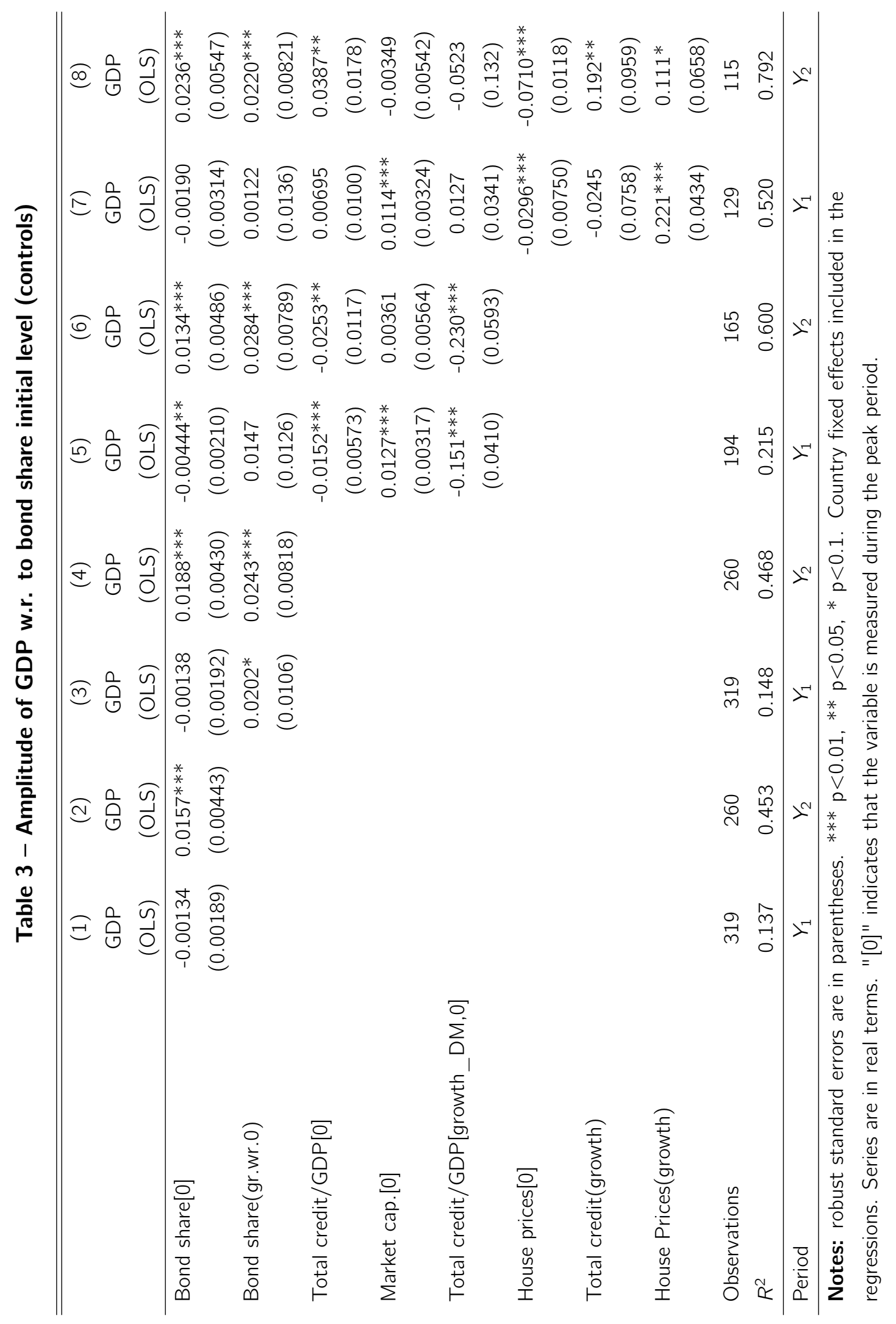


Table 3 reports the regression coefficients for bond share variables and financial markets developments variables. Consistently with the literature, we find a negative relation between financial markets developments before the recession and the GDP growth after the recession starts. More precisely, the total credit growth one year before the peak, high total credit to GDP ratio at the peak and high real estate prices at the peak are associated with deeper recessions. Interestingly, the growth rates of these variables after the peak are positively correlated with output. The sign of regression coefficients for these variables differ according to the number of controls introduced which is not surprising given their high correlation. However, the corporate debt structure variables (initial value and growth rate of bond share) remain positively and significantly correlated with the GDP variation regardless of the regression specification, see columns (5)-(8). Hence, we conclude that there exists a specific interaction between the corporate debt structure and the GDP growth which is independent from the developments on other financial markets.

\subsection{On the role of Credit in Economic Recovery}

Given the substitution between loans and bonds, the dynamics of credit in the economy is determined by the structure of corporate debt. For a given substitution between the two sources of debt, the growth of credit would be higher in economies where bonds are an important part of the corporate debt. ${ }^{17}$ The role of credit in economic recovery is however controversial since Calvo et al. (2006) pointed out the existence of "phoenix miracles" or creditless recoveries - when the recovery of output is accomplished without a recovery of credit. In a creditless recovery, the economic recovery is not driven by the external financing of firms on financial markets but rather by the use of idle capacity of production or trade credit between firms. The identification of such miracles is however highly sensitive to the definition of credit as a stock variable, in deviation with respect to its value at the peak, or as a flow variable, in deviation with respect to its value at the previous period. Biggs et al. (2010) show that the creditless recoveries identified by Calvo et al. (2006) are no longer puzzling when the the flow of new credit is considered instead of the stock of credit as done by Calvo et al. (2006). Consistently with this literature, we investigate the role of credit in the economic recovery for our panel of recessions by considering both its deviation with respect to the peak value and its quarterly growth rate.

Results are reported in Table 4. Columns (2) and (6) illustrate the importance of the specification of the credit series. When credit is considered as a stock as in Calvo et al.

\footnotetext{
${ }^{17}$ Using the notation $c$ for total credit, $b$ for bonds, and $\ell$ for loans: the growth rate of credit is: $\widehat{c}_{t, k, i}=$ $s_{t-1, k, i} \times\left(\widehat{b}_{t, k, i}-\widehat{\ell}_{t, k, i}\right)+\widehat{\ell}_{t, k, i}$, where $\widehat{b}_{t, k, i}-\widehat{\ell}_{t, k, i}$ measures the intensity of the substitution process.
} 
(2006), the absence of significant correlation between credit and real GDP deviation may support the creditless view of recovery developed by Calvo et al. (2006). But, when credit is considered as a flow, the relation between credit and real GDP is no longer puzzling: more credit is associated with a stronger recovery of real GDP as in Biggs et al. (2010) and Abiad et al. (2011). Columns (3)-(4) and (7)-(8) suggest that the relationship between credit and output dynamics depends on the structure of corporate debt. If we consider the recessions in economies where the initial value of bond share is above its median, the correlation between credit and real GDP becomes significant at the $1 \%$ level of significance for both measures of credit (as a stock or as a flow). For other recessions, the correlation remains not significant for the credit as a stock - see column (3) - and becomes less strong and less significant for the credit as a flow - see column (7). Overall, the link between credit and output is stronger in economies with a high bond share than in those with a low value of bond share.

Recoveries uncorrelated with credit are observed in our panel of recessions when the financing of corporations is mainly based on bank financing. When bond financing represents a sizable share of corporate debt, output and credit recoveries are positively correlated. These findings are consistent with the literature that demonstrated a positive role of credit in recoveries and that credit-less recoveries are most likely to be observed in the context of bank crisis, see Abiad et al. (2011), Coricelli and Roland (2011), and Bijsterbosch and Dahlhaus (2011). Columns (1) and (5) of Table 4 show the joint impact of total credit and corporate debt structure. The coefficients of bond share variables are still significantly different from zero at the $1 \%$ or $5 \%$ levels level of significance when we consider credit series as controls in the regression. Credit variables are also significant (even if it is only at the $10 \%$ level of significance), especially for the credit as a stock in interaction with the initial value of bond share. The column (1) confirms the role of the structure of corporate debt in the relation between credit and real GDP dynamics. The higher is the initial value of bond share, the stronger is the correlation of credit with the real GDP because of the substitution process described in Section 3.

\subsection{Robustness Checks}

This section summarizes a set of robustness checks of our main results.

Quarterly dummies. To characterize the business cycle behavior of corporate debts in Section 3, we introduced annual dummy regressors around peaks whereas the frequency of our panel is quarterly. We conduct the robustness check of our results when quarterly dummy regressors are considered, each quarter corresponding to different dummy variables. 
Table 4 - Corporate debt structure, Total credit and Recovery

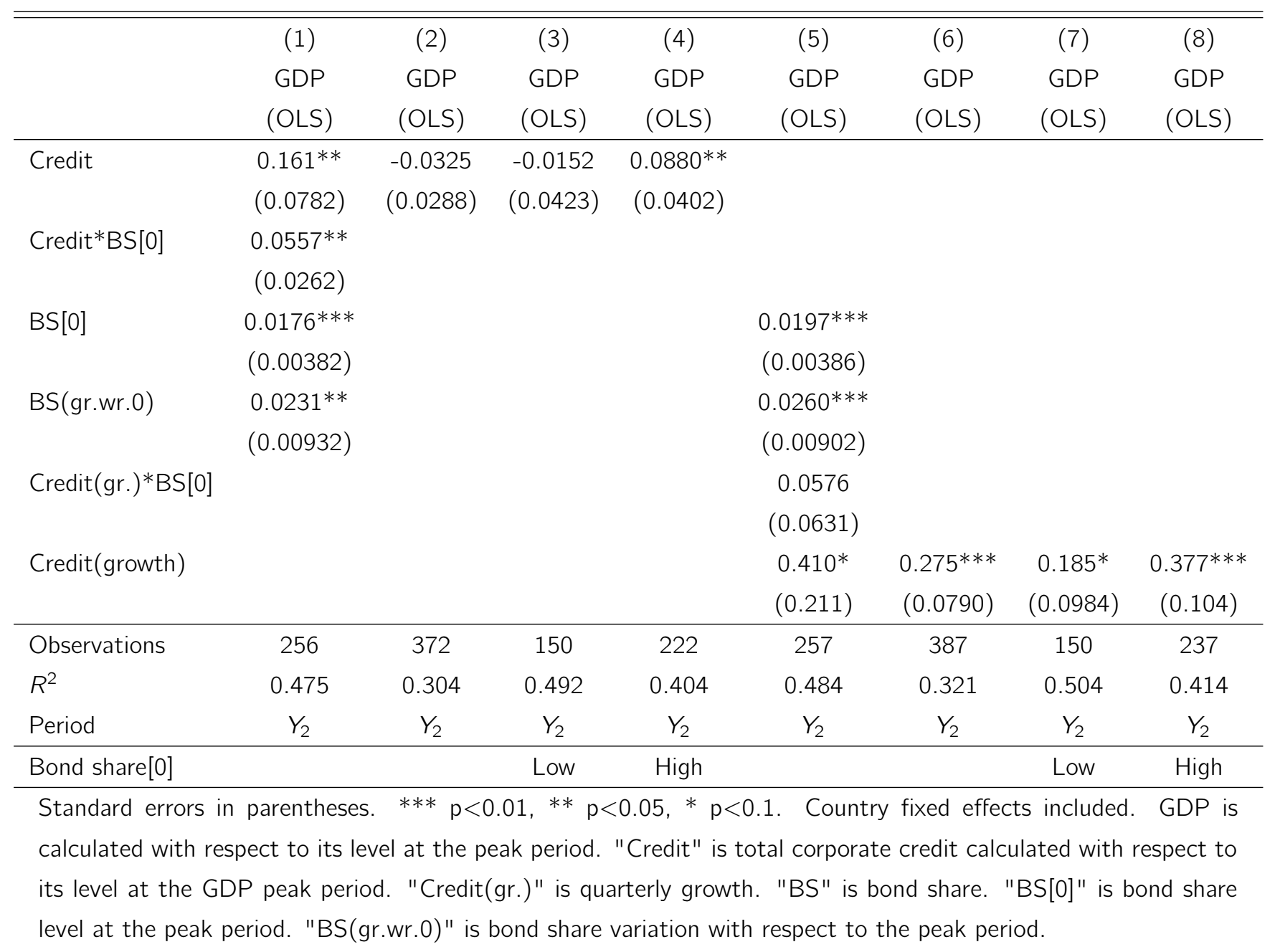


Tables A.3 and A.4 of the Appendix reproduce the Table 1. The business cycle behavior of corporate debts remains the same whether the annual or quarterly dummy regressors are used.

Growth rate of real GDP. The dynamics of real GDP is measured by its log-deviation with respect to the peak value. To assess the robustness of the results, we replicate our main empirical analysis considering the growth rates of real GDP instead of the log-deviation which is actually the cumulated sum of the growth rates. Tables A.5, A.6 and Figure B.1 replicate Tables 2, 3 and Figure 1, respectively, and confirm the patterns exhibited in Sections 3 and 4.

Excluding the United States. The United States is a special case in our panel because the series for this economy start earlier (1951 against after 1989 for the other economies) and the share of bonds in its corporate debt structure is the highest. Table A.7 replicates the Table A. 6 while excluding the United States from the panel data. It shows that our results do not depend on the presence of this special economy in our panel.

Alternative bond share initial values. The initial value of bond share is robustly correlated with economic recovery in all our regressions. To check that this result is not specific to the selected date of the peak, we test the alternative periods for the initial bond share value. Tables A.8 of the Appendix reproduces the column (2) of the Table 2 with the average value of the bond share over different periods before and after the peak. In Table A.9 we take the average deviation of the bond share with respect to its mean value for different periods before and after the preak.

Duration of recoveries. Our main finding is that economies where non financial corporations have important access to bond market are equally depressed as the economies with smaller access during recessions but their recovery is stronger afterwards. This implies that the economies with high bond share should reach their pre-recession real GDP level faster, hence their recovery phase should be shorter. Table A.10 tests this prediction by regressing our two corporate debt structure variables, bond share value at the peak and its variation after the peak, on the duration of business cycle phases. Consistently with our previous results, we find that (i) the duration of the recession is not correlated with the bond share variables, and (ii) the duration of the recovery phase is shorter in economies with high bond share values.

Recoveries after trough. Figure 3 and Table A.10 show that the dates of trough differ with respect to the structure of corporate debt. Therefore, interpreting the second year after the peak (namely $Y 2$ ) as the recovery might be misleading as it may correspond to 
a recession phase in an economy with low values of bond share. To account for this issue, Table A.11 in Appendix reproduces the Table 3 with the exact start of the recovery, i.e. after the trough. It confirms the positive association of the initial value of bond share and the real GDP growth during the economic recovery.

Investment. If bond share interacts with output trough the amount of credit in the economy, it is sensible to expect that bond share interacts equally with investment since new credit is used by non-financial corporations as an external source of investment financing. In Appendix, we reproduce our main regressions by considering the deviation of real investment instead of real GDP. Table A.12 and Figure B.3 exhibit strong positive correlation between the share of bonds in total credit and real investment during the second year after the peak. The economies with higher initial bond share and bond share increase after the peak experience not only higher GDP but also higher investment recovery.

Banking crisis. During banking crisis, the positive interaction between output and bond share may be reinforced since the ability of banks to supply credit is damaged. To test this prediction, we include in our benchmark regression a dummy variable which is equal to one if the recession occurs together with a banking crisis using the database of Laeven and Valencia (2013). Columns (1)-(2) of Table A.13 show that bank crisis are associated with lower output growth with respect to its peak value, especially during the second year. This result is consistent with the recent literature on business and financial cycles, e.g. Bordo et al. (2001), Dell'Ariccia et al. (2008), and Jordà et al. (2011). Taking into account this effect of banking crisis does not modify substantially the interaction between output and the bond share variables. Columns (3)-(4) of Table A.13 consider an interaction between the initial value of bond share and the bankig crisis dummy variable. The coefficient of this variable is positive and significantly different from zero for the second year: the interaction between output and the initial value of bond share is stronger in recessions with banking crisis than in normal recessions.

Firm size. It is a well-established fact in corporate finance that there exists a positive relation between the firm size and the access to debt markets. Indeed, small firms rely almost exclusively on bank finance while large firms finance themselves also by issuing debt securities. Therefore, the positive interaction between output dynamics and bond share that we found in previous section may be the consequence of the firm size structure: in an economy with a large share of small firms, the bond share is low because these firms rely on banking finance and the recovery weak because small firms are more fragile than large firms. Unfortunately, measures of the firm size are scarce and unavailable over a long period of time - see Poschke (2014) for a recent attempt to measure the firm size distribution 
across countries. Data are however provided for the recent period by the OECD. We use these data for the year 2005 to construct a measure of firm size distribution as the ratio of the value added by large firms (250+ employees) divided by the value added by small firms (1-49 employees). This variable is then introduced in our benchmark regression. Results should be interpreted carefully since it imposes the distribution observed in 2005 for all years and the data are not available for all countries. Column (1) in Table A.14 confirms our intuition: the recovery is faster in economies where the value added by large firms with respect to value added by small firms is higher. In order to measure whether the relation between initial bond share and output is affected by the relative share of value added by large firms, we introduce an interaction term between these two variables. Column (2) shows that the interaction coefficient is positive and significantly different from zero.

The coefficient of bond share is negative whereas it was positive in all our previous regressions. Nevertheless, the overall interaction between bond share and output growth should be measured by considering both bond share and interaction coefficients. Indeed, coefficient of the interaction variable is positive: the larger is the relative share of large firms, the higher is the positive correlation between output dynamics and the initial value of bond share. Column (2) shows that the elasticity of bond share with respect to the initial value of bond share is $-0.287+0.0330 \times \rho$, where $\rho$ stands for the ratio of value added by large firms to value added by small firms. This elasticity is positive if $\rho>0.287 / 0.0330=0.86$. For our panel of countries, the variable $\rho$ varies between 0.52 and 7.99 with a mean value of 1.86. Therefore, the elasticity is positive for most of the countries. These results are maintained when the growth rate of bond share is also introduced in the regression, see Column (3).

Credit. Table A.15 shows the coefficient of the accounting equation introduced in the footnote 4.3 to exhibit the positive correlation between bond share and credit expansion during the second year. The mean behavior of total credit is depicted in Figure B.5.

\section{Substitution Between Loans and Bonds During the Recovery: A Theoretical Explanation}

Adrian et al. (2012) build a model for the credit market based on Shin (2012) to account for the bond-loan substitution in the U.S. Great Recession. However, our empirical evidence shows that the substitution appears in recoveries for most of the economies. Therefore, we extend the model of Shin (2012) in a way that is consistent with our empirical evidence. The Shin (2012)'s model is a static model with one-period decision. We consider an 
additional period to distinguish the recession phase from the recovery phase which have different properties in our empirical analysis. The full resolution of the model is detailed in Appendix C.

\subsection{Assumptions}

We assume the following timing of events:

- $t=0$ : is the regular period, before the recession

- $t=1$ : is the recession period, after the peak

- $t=2$ : is the recovery period that follows the recession

- $t=3$ : the economy returns to the regular state $t=0$

The business cycle is driven by time-variations in the exogenous default rate of corporate firms $\varepsilon_{t}$ and in the aggregate state $z_{t}$. Recessions are period of high probability of defaulting for firms $\varepsilon_{t}$ and low value for $z_{t}$.

The bank lends out the amount $C_{t}^{B}$ of credit at the interest rate $r_{t}$ and expects as revenue $\left(1+r_{t}\right) C_{t}^{B}$. The lending is financed by the combination of capital, $E_{t}$, and bank debt, $L_{t}$. The bank owes $(1+f) L_{t}$ where $f$ is the interest rate for bank debt. Each unit of credit finances one project that succeeds with a probability $\varepsilon$ and fails otherwise with a probability $1-\varepsilon$.

The key assumption in Shin (2012) is that banks are subject to a Value-at-Risk (VaR) constraint in their decision making. The bank takes its equity as given and chooses the amounts of credit $C_{t}^{B}$ and of funding $L$ such that probability of bank default is equal to the threshold $0<\alpha<1$. Shin (2012) also assumes that banks are risk-neutral and maximize profit. Therefore, the VaR constraint binds whenever expected profit from lending is positive and it is optimal for banks to limit lending so as to keep the probability of its own failure to $\alpha{ }^{18}$

We introduce a second constraint in the model: the accumulation of wealth by banks. In the static model of Shin (2012), the balance sheet of banks reduces to $C^{B}=E+L$ where $C^{B}$ stands for credit to firms, $E$ for bank capital, and $L$ for bank liabilities. We add to this balance sheet $\Pi$ for earnings $(\Pi>0)$ or losses $(\Pi<0)$ realized by banks, which are

18 Adrian and Shin (2014) show evidence consistent with a rule of thumb for banks that keep constant the $\mathrm{VaR}$. They also provide the micro-foundations for the $\mathrm{VaR}$ constraint as the outcome of the standard contracting framework with risk-shifting moral hazard. 
transferred for the next period. The new balance sheet constraint is

$$
C_{t}^{B}=E_{t}+L_{t}
$$

where bank capital is given by

$$
E_{t}=E_{t-1}+\Pi_{t-1}
$$

We solve the model for

$$
\Pi_{1}<\Pi_{0,2}=0
$$

$\Pi_{1}<0$ : financial losses during the recession $(t=1)$ reduce the liabilities of banks for the recovery phase $(t=2) . \Pi_{t \neq 1}=0$ : to ensure the equivalence between our setup and that of Shin (2012), there is no earnings/losses in period $t=\{0,2\}$ or, equivalently, all earnings are distributed as dividends.

\subsection{Credit Market Equilibrium}

We show in the Appendix $C$ that the financial losses of banks are

$$
\Pi_{t}=\psi\left(\alpha, \varepsilon_{t}, z_{t}, \rho\right)\left(1+r_{t}\right) C_{t}^{B}
$$

where $\alpha$ is the $\mathrm{VaR}$ probability. The function $\psi($.$) and the correlation between idiosyncratic$ and common factors $\rho$ are defined in Appendix C. To verify the assumption (7), we impose a sequence of aggregate shocks $\left(\varepsilon_{t}, z_{t}\right)$ such that

$$
\psi\left(\alpha, \varepsilon_{1}, z_{1}, \rho\right)<\psi\left(\alpha, \varepsilon_{0,2}, z_{0,2}, \rho\right)=0
$$

The supply of credit is the sum of the supplies by banks, $C_{t}^{B}$, and by households, $C_{t}^{H}$, which are the bond investors in this economy. As in Adrian et al. (2012), households are risk-averse with mean-variance preferences and hold a portfolio of risky assets (namely bonds) and risk free assets. The risk tolerance of households is set to the unity.

The credit market equilibrium is

$$
E \times \frac{1+\frac{\psi\left(\alpha, \varepsilon_{t-1}, z_{t-1}, \rho\right)\left(1+r_{t-1}\right)}{1-\varphi\left(\alpha, \varepsilon_{t-1}, \rho\right)\left(1+r_{t-1}\right) /(1+f)}}{1-\varphi\left(\alpha, \varepsilon_{t}, \rho\right)\left(1+\pi_{t}\right) /\left[\left(1-\varepsilon_{t}\right)(1+f)\right]}+T \times \frac{\left(1-\varepsilon_{t}\right)\left(\frac{1+\pi_{t}}{1-\varepsilon_{t}}\right)-1}{\sigma_{t}^{2}\left[\left(1+\pi_{t}\right) /\left(1-\varepsilon_{t}\right)\right]^{2}}=C^{D}\left(1+\pi_{t}\right)
$$

where $C^{D}($.$) is the credit demand as a function of (1+\pi)$ the interest rate premium, $T$ the size of the population of bond investors and $\sigma$ the risk measure of bonds. For $\psi()=$.0 , our equation (10) is equivalent to the equation (19) of Shin (2012). In this case, only $\varepsilon$ impacts the credit market equilibrium through the function $\varphi($.$) . This function determines$ 
Figure 4 - The credit cycle
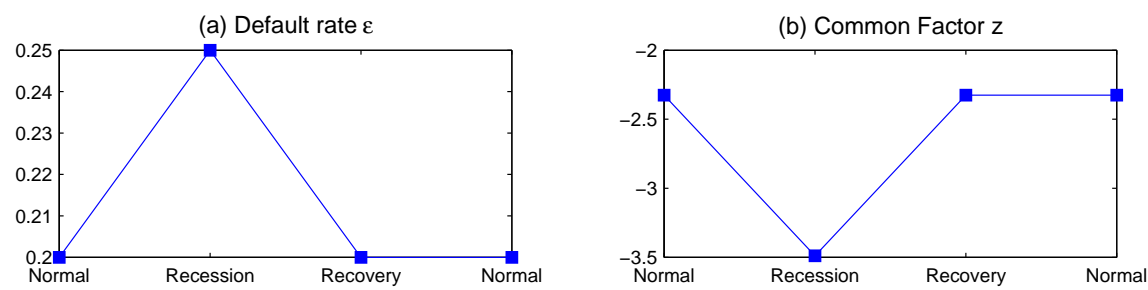

(c) Premium $\pi$

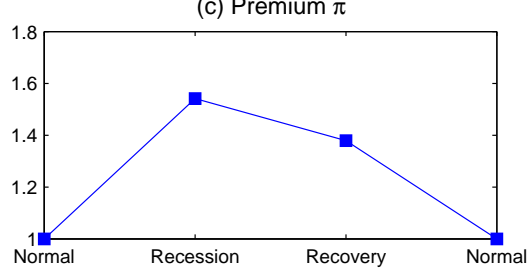

(d) Total credit $C^{D}$
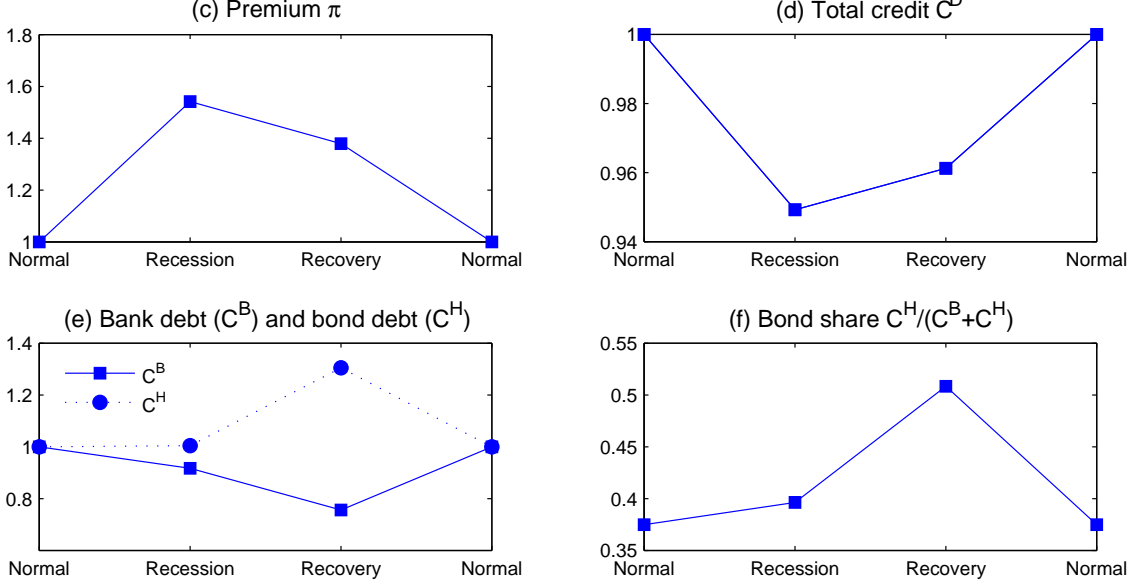

Panels (a) and (b) show the exogenous shocks, panels (c) and (d) the endogenous reaction on the credit market, and panels $(e)$ and $(f)$ the time-varying composition of the credit supply.

the ratio of the bank debt to bank credit supply - see Appendix C. For $\psi()<$.0 , both $\varepsilon$ and $z$ impact the credit market equilibrium through the function $\varphi($.$) , as in the previous$ case, but also through for the financial losses determined by $\psi($.$) given z_{t-1}$, the size of the recession.

\subsection{Numerical Simulations}

In Appendix C, we compute the growth factor of credit between periods. Between period 0 and 1 our model behaves exactly as in Shin (2012). A rise of the defaulting probability of firms during the recession, $\varepsilon(1)>\varepsilon(0)$, is followed by an increase in the interest rate premium, a fall in credit demand by firms and credit supply by banks, but an increase in credit supply by bond investors if their demand is not too elastic. After the recession, during period 2, our specific mechanism dampens the credit supply by banks still affected by the financial losses of the recession.

The figure 4 illustrates numerically a typical credit cycle in this model. The model is simulated for the following values of the structural parameters: $T=3, E=5, \alpha=0.01$, $\rho=0.3, \epsilon=0.20, f=0, \pi=0.10, \underline{d}=10, \bar{d}=1$, and $\delta=-0.5 .^{19}$ The recovery

\footnotetext{
${ }^{19}$ These values are close to those used by Adrian et al. (2012).
} 
Figure 5 - The credit cycle for two economies

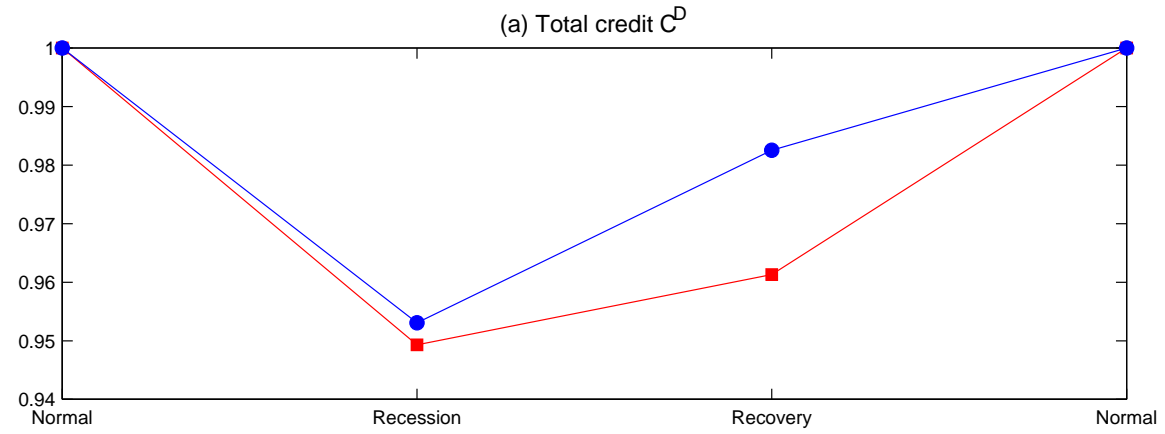

(b) Premium $\pi$

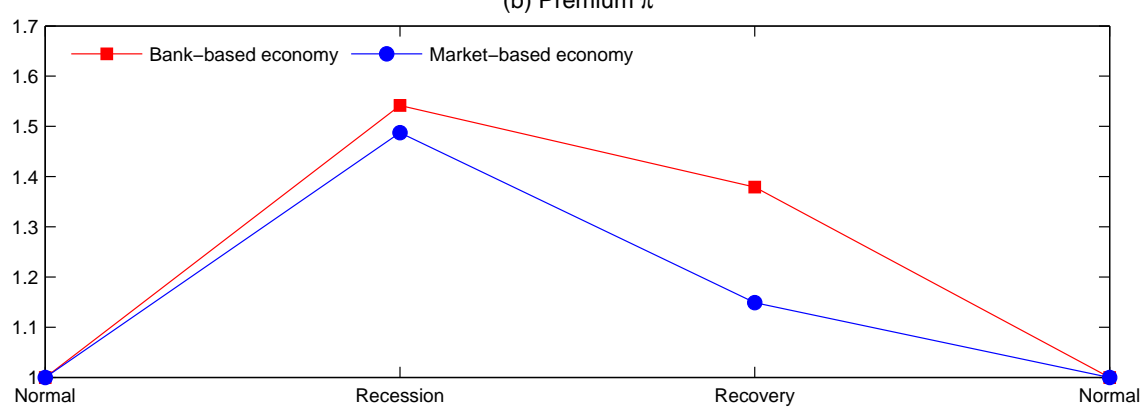

For the same shocks depicted in Figure 4, panel (a) compares the total credit and panel (b) the interest rate premium in the two economies. The parameters $T$ and $E$ are set equal to $T=5$ and $E=3$ in the market-based economy (lines with circles) and to $T=3$ and $E=5$ in the bank-based economy (lines with squares).

is not completed in period 2, even if the fundamentals are restored, and the bond share increases during the recession, as explained by Adrian et al. (2012), and once again during the recovery due to the bank financial losses.

The figure 5 compares two economies which differ with respect to the size of the populations of bankers and bond investors. The previous case is referred to as the bank-based economy. The values are unchanged in the market-based economy except for the sizes of household population, which is set to $T=5$, and of the bank capital, $E=3$. The recovery is faster in the economy with the higher share of bond investors (see the blue lines with circle symbols) when compared with the economy with the highest share of bankers (see the blue lines with square symbols). The pattern of bond share in figure 5 is similar to that we found in the data - see figure 3.

The interest rate premium plays an important role in the model. It is precisely because the interest rate is higher that the supply of credit by bond investors increases when the supply of credit by banks declines. A detailed analysis of the behavior of interest rates for various debt instruments is beyond the scope of this paper due to the lack of comparable series between instruments and economies in our panel data - see Francis et al. (2014) for 
such analysis using micro-level data. Therefore, we focused on the credit quantities in our empirical analysis. Nevertheless, we show in the Appendix that the business cycle behavior of interest rates for our panel of recessions is consistent with that described in the model - see Figure B.6 and Table A.16. The credit spreads for loans and bonds are above their peak values during the two years following a peak.

\section{Conclusion}

The recent crisis has renewed the needs for understanding the links between financial markets and business cycles. In this paper, we contribute to this literature by showing the importance of the structure of corporate debt. We show that the substitution process between bonds and bank loans is a regular feature of business cycles and this process is related to macroeconomic performance. The economies with higher share of bonds in corporate debt experience stronger recoveries. Our findings seem also relevant for the economic policy design, especially in advanced economies such as the Euro area where the corporate debt markets are less developed. Indeed, the policies aimed at developing corporate debt markets could be a useful complement to bank recapitalization policies. 


\section{References}

Abiad, A., Li, B. G., and Dell'Ariccia, G. (2011). Creditless recoveries. IMF Working Papers, pages $1-30$.

Adrian, T., Colla, P., and Shin, H. S. (2012). Which Financial Frictions? Parsing the Evidence from the Financial Crisis of 2007-9. Technical report, National Bureau of Economic Research.

Adrian, T. and Shin, H. S. (2014). Procyclical leverage and value-at-risk. Review of financial studies, 27(2):373-403.

Allard, J. and Blavy, R. (2011). Market Phoenixes and Banking Ducks Are Recoveries Faster in Market Based Financial Systems? IMF Working Papers 11/213, International Monetary Fund.

Becker, B. and Ivashina, V. (2014). Cyclicality of credit supply: Firm level evidence. Journal of Monetary Economics, 62:76-93.

Bernanke, B. S. and Gertler, M. (1989). Agency costs, net worth, and business fluctuations. The American Economic Review, 79(1):14-31.

Biggs, M., Mayer, T., and Pick, A. (2010). Credit and Economic Recovery: Demystifying Phoenix Miracles. Available at SSRN 1595980.

Bijsterbosch, M. and Dahlhaus, T. (2011). Determinants of credit-less recoveries. Technical report, European Central Bank.

Bordo, M., Eichengreen, B., Klingebiel, D., and Martinez-Peria, M. S. (2001). Is the crisis problem growing more severe? Economic policy, 16(32):51-82.

Bordo, M. D. and Haubrich, J. G. (2012). Deep Recessions, Fast Recoveries, and Financial Crises: Evidence from the American Record. Working Paper 18194, National Bureau of Economic Research.

Bry, G. and Boschan, C. (1971). Programmed selection of cyclical turning points. In Cyclical Analysis of Time Series: Selected Procedures and Computer Programs, pages 7-63. UMI.

Burns, A. F. and Mitchell, W. C. (1946). Measuring business cycles. NBER Books.

Calvo, G. A., Izquierdo, A., and Talvi, E. (2006). Sudden stops and phoenix miracles in emerging markets. The American economic review, 96(2):405-410.

Carlstrom, C. T. and Fuerst, T. S. (1997). Agency costs, net worth, and business fluctuations: A computable general equilibrium analysis. The American Economic Review, pages 893-910. 
Claessens, S., Kose, M. A., and Terrones, M. E. (2012). How do business and financial cycles interact? Journal of International Economics, 87(1):178-190.

Coricelli, F. and Roland, I. (2011). How do credit conditions shape economic recoveries?

Crouzet, N. (2014). Corporate debt structure and the macroeconomy. In Annual Meeting of the American Economic Association, Philadelphia, pages 3-5.

De Fiore, F. and Uhlig, H. (2011). Bank Finance versus Bond Finance. Journal of Money, Credit and Banking, 43(7):1399-1421.

De Fiore, F. and Uhlig, H. (2012). Corporate debt structure and the financial crisis. 2012 Meeting Papers, pages 1-43.

Dell'Ariccia, G., Detragiache, E., and Rajan, R. (2008). The real effect of banking crises. Journal of Financial Intermediation, 17(1):89-112.

Diamond, D. (1991). Monitoring and reputation: The choice between bank loans and directly placed debt. Journal of political Economy, 99(4):689-721.

European Commission (2014). Communication from the Commission to the European Parliament and the Council on Long-Term Financing of the European Economy. $\operatorname{COM}(2014) 168$ final.

Fatás, A. and Mihov, I. (2013). Recoveries. Technical report, CEPR Discussion Papers.

Francis, J. L., Aykut, D., and Tereanu, E. (2014). The cost of private debt over the credit cycle. Journal of International Money and Finance, 41:146-181.

Freixas, X. and Rochet, J. C. (2010). Microeconomics of banking. The MIT Press, 2nd editio edition.

Harding, D. and Pagan, A. (2002). Dissecting the cycle: a methodological investigation. Journal of monetary economics, 49(2):365-381.

Herring, R. J. and Chatusripitak, N. (2007). 5. The case of the missing market: the bond market and why it matters for financial development. Recent financial crises: analysis, challenges and implications, page 148.

Holmstrom, B. and Tirole, J. (1997). Financial intermediation, loanable funds, and the real sector. the Quarterly Journal of economics, 112(3):663-691.

Jordà, O., Schularick, M., and Taylor, A. M. (2011). Financial crises, credit booms, and external imbalances: 140 years of lessons. IMF Economic Review, 59(2):340-378.

Jordà, O., Schularick, M., and Taylor, A. M. (2013). When Credit Bites Back. Journal of Money, Credit and Banking, 45(s2):3-28.

Kashyap, A. K., Stein, J. C., and Wilcox, D. W. (1993). Monetary policy and credit conditions: Evidence from the composition of external finance. The American Economic 
Review, 83(1):78-98.

Laeven, L. and Valencia, F. (2013). Systemic banking crises database. IMF Economic Review, 61(2):225-270.

Levine, R. (2005). Finance and growth: theory and evidence. Handbook of economic growth, 1:865-934.

Oliner, S. D. and Rudebusch, G. D. (1996). Monetary policy and credit conditions: evidence from the composition of external finance: comment. The American Economic Review, pages 300-309.

Poschke, M. (2014). The Firm Size Distribution across Countries and Skill-Biased Change in Entrepreneurial Technology. IZA Discussion Papers 7991, Institute for the Study of Labor (IZA).

Rodriguez-Palenzuela, D., Darracq Paries, M., Carboni, G., Ferrando, A., Köhler Ulbrich, P., Zachary, M.-D., Geiger, F., Rupprecht, M., Raudsaar, T., McCann, F., and Others (2013). Corporate Finance and Economic Activity in the Euro Area: Structural Issues Report 2013. ECB Occasional Paper, No. 151.

Schularick, M. and Taylor, A. M. (2012). Credit Booms Gone Bust: Monetary Policy, Leverage Cycles, and Financial Crises, 1870-2008. The American Economic Review, 102(2):1029-1061.

Shin, H. S. (2012). Global Banking Glut and Loan Risk Premium. IMF Economic Review, 60(2):155-192. 
Appendix

A. Additional Tables 
Table A.1 - Descriptive statistics for bond share

\begin{tabular}{|c|c|c|c|c|c|}
\hline Country & Year(min) & Year(max) & Mean & Min & Max \\
\hline Australia & 1989 & 2013 & 0.17 & 0.13 & 0.20 \\
\hline Austria & 1995 & 2013 & 0.10 & 0.02 & 0.18 \\
\hline Belgium & 1989 & 2013 & 0.06 & 0.03 & 0.12 \\
\hline Canada & 1989 & 2013 & 0.20 & 0.15 & 0.26 \\
\hline China & 2006 & 2013 & 0.05 & 0.02 & 0.07 \\
\hline Czech Republic & 2006 & 2013 & 0.08 & 0.05 & 0.15 \\
\hline Denmark & 1999 & 2013 & 0.06 & 0.01 & 0.11 \\
\hline Finland & 1989 & 2013 & 0.12 & 0.08 & 0.15 \\
\hline France & 1989 & 2013 & 0.18 & 0.14 & 0.22 \\
\hline Germany & 1989 & 2013 & 0.06 & 0.03 & 0.09 \\
\hline Hong Kong & 1998 & 2013 & 0.08 & 0.04 & 0.12 \\
\hline Hungary & 1997 & 2013 & 0.02 & 0.00 & 0.03 \\
\hline Ireland & 2009 & 2013 & 0.01 & 0.01 & 0.01 \\
\hline Italy & 1989 & 2013 & 0.05 & 0.03 & 0.09 \\
\hline Japan & 1997 & 2013 & 0.18 & 0.15 & 0.21 \\
\hline Luxembourg & 2008 & 2013 & 0.12 & 0.05 & 0.17 \\
\hline Netherlands & 1990 & 2013 & 0.10 & 0.04 & 0.19 \\
\hline Norway & 1995 & 2013 & 0.12 & 0.08 & 0.16 \\
\hline Portugal & 1989 & 2013 & 0.10 & 0.04 & 0.16 \\
\hline Singapore & 2000 & 2013 & 0.40 & 0.27 & 0.50 \\
\hline Spain & 1989 & 2013 & 0.04 & 0.01 & 0.10 \\
\hline Sweden & 2001 & 2012 & 0.02 & 0.01 & 0.04 \\
\hline Thailand & 1994 & 2013 & 0.14 & 0.00 & 0.31 \\
\hline United Kingdom & 1989 & 2013 & 0.22 & 0.02 & 0.29 \\
\hline United States & 1951 & 2013 & 0.51 & 0.38 & 0.74 \\
\hline Total & 1951 & 2013 & 0.17 & 0.00 & 0.74 \\
\hline
\end{tabular}


Table A.2 - Business cycles: basic features

\begin{tabular}{|c|c|c|c|c|c|}
\hline & Nr Events & Duration & Amplitude & Cumulative loss & Slope \\
\hline Recession & Peaks: 93 & $4.00[4.32]$ & $-2.09 \%[-1.79 \%]$ & $-6.10[-10.32]$ & $-0.62[-0.81]$ \\
\hline Obs. & & 84 & 88 & 88 & 84 \\
\hline Recovery & Troughs: 89 & $3.00[3.84]$ & $2.38 \%[3.22 \%]$ & & $0.77[1.12]$ \\
\hline Obs & & 51 & 76 & & 51 \\
\hline
\end{tabular}

Note: medians, [means]. 
Table A.3 - Bond share cycle (with respect to peak)

\begin{tabular}{|c|c|c|c|}
\hline & (1) & (1) & $(1)$ \\
\hline & $\begin{array}{c}\text { Bond share } \\
\text { (OLS) }\end{array}$ & $\begin{array}{l}\text { Loan } \\
\text { (OLS) }\end{array}$ & $\begin{array}{l}\text { Bond } \\
\text { (OLS) }\end{array}$ \\
\hline \multirow[t]{2}{*}{$Q_{1}$} & -0.000377 & 0.00779 & 0.00739 \\
\hline & $(0.0650)$ & $(0.0122)$ & $(0.0675)$ \\
\hline \multirow[t]{2}{*}{$Q_{2}$} & 0.00732 & 0.0159 & 0.0241 \\
\hline & $(0.0650)$ & $(0.0122)$ & $(0.0675)$ \\
\hline \multirow[t]{2}{*}{$Q_{3}$} & 0.0182 & $0.0209 *$ & 0.0429 \\
\hline & $(0.0652)$ & $(0.0122)$ & $(0.0678)$ \\
\hline \multirow{2}{*}{$Q_{4}$} & 0.0254 & $0.0230 *$ & 0.0524 \\
\hline & $(0.0659)$ & $(0.0123)$ & $(0.0685)$ \\
\hline \multirow{2}{*}{$Q_{5}$} & $0.132^{* *}$ & 0.0133 & $0.156^{* *}$ \\
\hline & $(0.0666)$ & $(0.0124)$ & $(0.0692)$ \\
\hline \multirow[t]{2}{*}{$Q_{6}$} & $0.149 * *$ & 0.00984 & $0.177^{* *}$ \\
\hline & $(0.0687)$ & $(0.0127)$ & $(0.0714)$ \\
\hline \multirow[t]{2}{*}{$Q_{7}$} & $0.147^{* *}$ & 0.0193 & $0.184^{* *}$ \\
\hline & $(0.0700)$ & $(0.0130)$ & $(0.0727)$ \\
\hline \multirow[t]{2}{*}{$Q_{8}$} & $0.154^{* *}$ & $0.0255^{*}$ & $0.195^{* * *}$ \\
\hline & $(0.0713)$ & $(0.0131)$ & $(0.0742)$ \\
\hline \multirow[t]{2}{*}{$Q_{-1}$} & 0.00467 & 0.0141 & 0.00784 \\
\hline & $(0.0687)$ & $(0.0128)$ & $(0.0708)$ \\
\hline \multirow[t]{2}{*}{$Q_{-2}$} & 0.0846 & $0.0294^{* *}$ & 0.113 \\
\hline & $(0.0699)$ & $(0.0130)$ & $(0.0721)$ \\
\hline \multirow[t]{2}{*}{$Q_{-3}$} & -0.00128 & $0.0420 * * *$ & 0.0280 \\
\hline & $(0.0706)$ & $(0.0131)$ & $(0.0731)$ \\
\hline \multirow[t]{2}{*}{$Q_{-4}$} & 0.00664 & $0.0651^{* * *}$ & 0.0546 \\
\hline & $(0.0724)$ & $(0.0135)$ & $(0.0750)$ \\
\hline \multirow[t]{2}{*}{$Q_{-5}$} & -0.0172 & $0.0830 * * *$ & 0.0408 \\
\hline & $(0.0737)$ & $(0.0137)$ & $(0.0762)$ \\
\hline \multirow[t]{2}{*}{$Q_{-6}$} & -0.0285 & $0.0992^{* * *}$ & 0.0433 \\
\hline & $(0.0766)$ & $(0.0142)$ & $(0.0793)$ \\
\hline \multirow[t]{2}{*}{$Q_{-7}$} & -0.0404 & $0.127^{* * *}$ & 0.0507 \\
\hline & $(0.0790)$ & $(0.0146)$ & $(0.0817)$ \\
\hline \multirow[t]{2}{*}{$Q_{-8}$} & -0.000615 & $0.165^{* * *}$ & 0.129 \\
\hline & $(0.0833)$ & $(0.0154)$ & $(0.0862)$ \\
\hline Observations & 1,079 & 1,095 & 1,072 \\
\hline$R^{2}$ & 0.086 & 0.318 & 0.093 \\
\hline
\end{tabular}


Table A.4 - Bond share cycle (annual growth)

\begin{tabular}{|c|c|c|c|c|c|}
\hline & $\begin{array}{c}\text { (1) } \\
\text { Bond share } \\
(\mathrm{OLS})\end{array}$ & & $\begin{array}{c}(2) \\
\text { Loan } \\
(\mathrm{OLS})\end{array}$ & & $\begin{array}{c}\text { (3) } \\
\text { Bond } \\
\text { (OLS) }\end{array}$ \\
\hline Bond share(Q1) & $\begin{array}{c}-0.000294 \\
(0.0255)\end{array}$ & Loan(Q1) & $\begin{array}{c}0.00407 \\
(0.00831)\end{array}$ & Bond(Q1) & $\begin{array}{r}-0.00842 \\
(0.0253)\end{array}$ \\
\hline Bond share(Q2) & $\begin{array}{c}0.0206 \\
(0.0254)\end{array}$ & Loan(Q2) & $\begin{array}{l}-0.00168 \\
(0.00831)\end{array}$ & Bond(Q2) & $\begin{array}{c}0.0142 \\
(0.0250)\end{array}$ \\
\hline Bond share(Q3) & $\begin{array}{c}0.0108 \\
(0.0252)\end{array}$ & Loan(Q3) & $\begin{array}{c}-0.0103 \\
(0.00821)\end{array}$ & Bond(Q3) & $\begin{array}{r}-0.00207 \\
(0.0248)\end{array}$ \\
\hline Bond share(Q4) & $\begin{array}{c}0.00893 \\
(0.0256)\end{array}$ & Loan(Q4) & $\begin{array}{c}-0.0203^{* *} \\
(0.00833)\end{array}$ & Bond(Q4) & $\begin{array}{r}-0.00812 \\
(0.0252)\end{array}$ \\
\hline Bond share(Q5) & $\begin{array}{c}0.0632 * * \\
(0.0261)\end{array}$ & Loan(Q5) & $\begin{array}{c}-0.0370 * * * \\
(0.00847)\end{array}$ & Bond(Q5) & $\begin{array}{c}0.0378 \\
(0.0257)\end{array}$ \\
\hline Bond share(Q6) & $\begin{array}{c}0.0847^{* * *} \\
(0.0275)\end{array}$ & Loan(Q6) & $\begin{array}{c}-0.0503^{* * *} \\
(0.00887)\end{array}$ & Bond(Q6) & $\begin{array}{c}0.0505^{*} \\
(0.0271)\end{array}$ \\
\hline Bond share(Q7) & $\begin{array}{c}0.0756^{* * *} \\
(0.0279)\end{array}$ & Loan(Q7) & $\begin{array}{c}-0.0496 * * * \\
(0.00911)\end{array}$ & Bond(Q7) & $\begin{array}{c}0.0391 \\
(0.0275)\end{array}$ \\
\hline Bond share(Q8) & $\begin{array}{c}0.0780 * * * \\
(0.0288)\end{array}$ & Loan(Q8) & $\begin{array}{c}-0.0546 * * * \\
(0.00935)\end{array}$ & Bond(Q8) & $\begin{array}{c}0.0338 \\
(0.0283)\end{array}$ \\
\hline Observations & 1,834 & Observations & 2,145 & Observations & 1,884 \\
\hline$R^{2}$ & 0.100 & $R^{2}$ & 0.126 & $R^{2}$ & 0.120 \\
\hline
\end{tabular}

Table A.5 - Corporate debt structure and GDP growth

\begin{tabular}{|c|c|c|c|c|c|c|c|c|}
\hline & (1) & (2) & (3) & (4) & (5) & (6) & (7) & (8) \\
\hline \multirow[t]{2}{*}{ growth } & GDP & GDP & GDP & GDP & GDP & GDP & GDP & GDP \\
\hline & (OLS) & (OLS) & (OLS) & (OLS) & (OLS) & (OLS) & (OLS) & (OLS) \\
\hline \multirow[t]{2}{*}{$\mathrm{BS}$} & -0.000986 & $0.00900 * * *$ & & & & & & \\
\hline & $(0.00154)$ & $(0.00185)$ & & & & & & \\
\hline \multirow[t]{2}{*}{$\mathrm{BS}[0]$} & & & -0.00166 & $0.00922^{* * *}$ & -0.00162 & $0.00855^{* * *}$ & & \\
\hline & & & $(0.00160)$ & $(0.00188)$ & $(0.00151)$ & $(0.00180)$ & & \\
\hline \multirow[t]{2}{*}{$\mathrm{BS}(\mathrm{gr} .0)$} & & & $0.0191 * * *$ & $0.00524 *$ & & & $0.0190 * * *$ & -0.00137 \\
\hline & & & $(0.00696)$ & $(0.00295)$ & & & $(0.00721)$ & $(0.00256)$ \\
\hline Obs. & 323 & 273 & 319 & 260 & 319 & 260 & 319 & 260 \\
\hline$R^{2}$ & 0.131 & 0.440 & 0.109 & 0.451 & 0.085 & 0.445 & 0.103 & 0.341 \\
\hline Period & $Y_{1}$ & $Y_{2}$ & $Y_{1}$ & $Y_{2}$ & $Y_{1}$ & $Y_{2}$ & $Y_{1}$ & $Y_{2}$ \\
\hline
\end{tabular}

Robust standard errors in parentheses. ${ }^{* * *} \mathrm{p}<0.01, * * \mathrm{p}<0.05,{ }^{*} \mathrm{p}<0.1$. Country fixed effects included. GDP is calculated in quarterly growth terms. $Y_{1}$ corresponds to one year after the peak. "BS" means bond share. "BS[0]" is bond share level at the peak period. "BS(gr.0)" is bond share variation with respect to the peak period. 


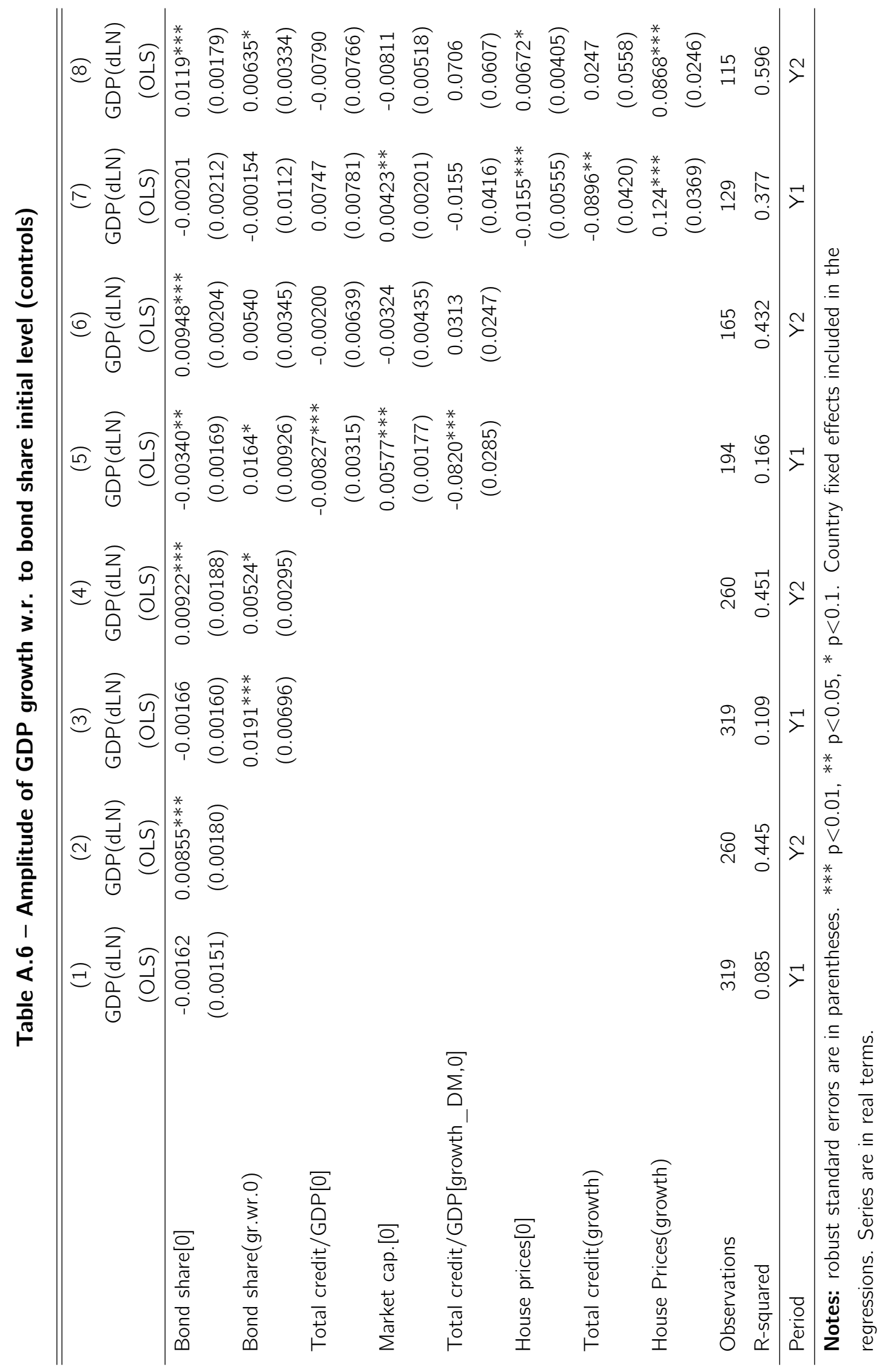




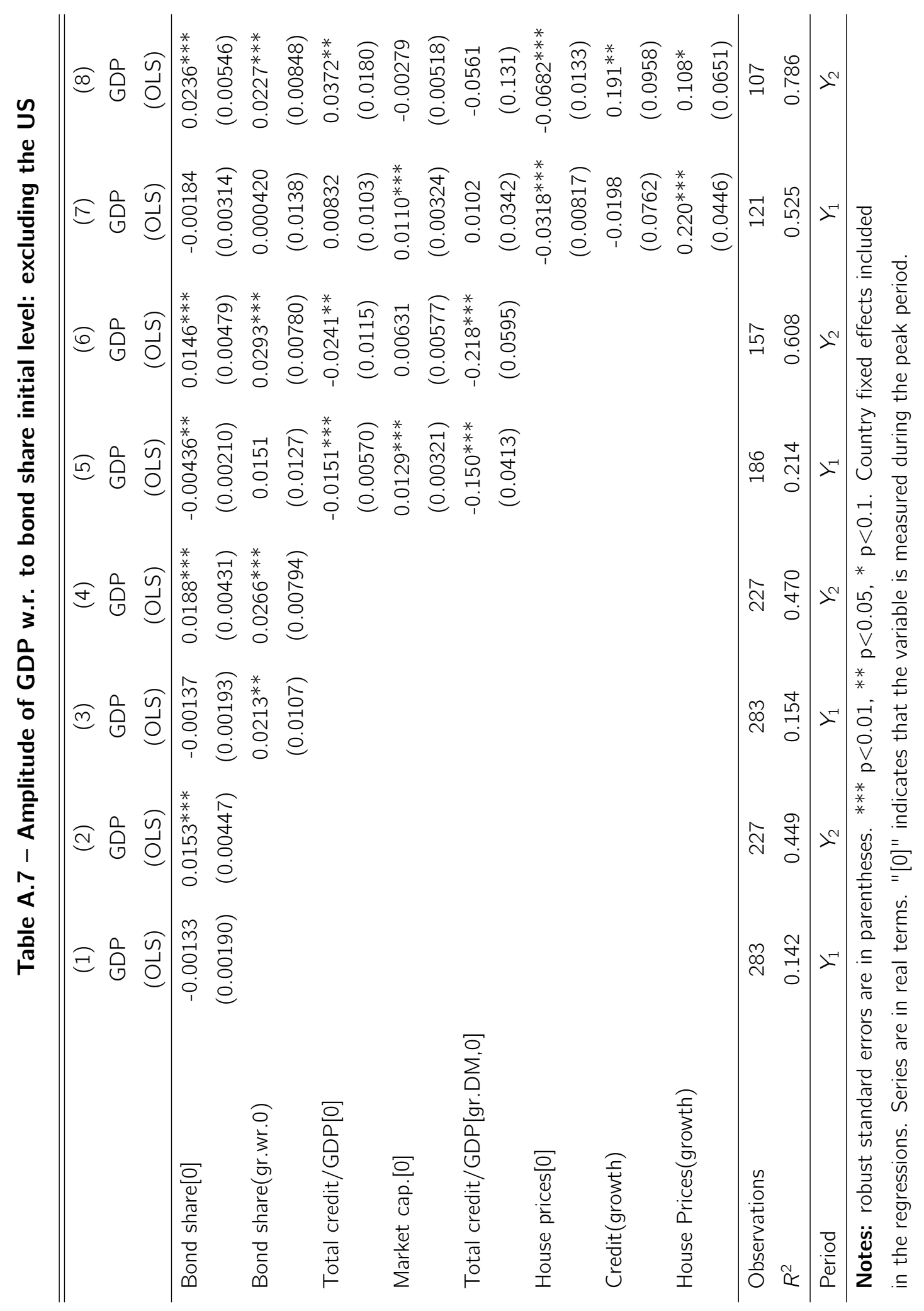


Table A.8 - Amplitude of GDP growth w.r. to bond share levels (RC)

\begin{tabular}{|c|c|c|c|c|c|c|c|c|}
\hline & (1) & (2) & (3) & (4) & (5) & (6) & (7) & (8) \\
\hline \multirow[t]{2}{*}{ A: peak } & GDP & GDP & GDP & GDP & GDP & GDP & GDP & GDP \\
\hline & (OLS) & (OLS) & (OLS) & (OLS) & (OLS) & (OLS) & (OLS) & (OLS) \\
\hline \multirow[t]{2}{*}{$\mathrm{BS}(0: 4)$} & -0.00128 & & & & $0.0164 * * *$ & & & \\
\hline & $(0.00232)$ & & & & $(0.00423)$ & & & \\
\hline \multirow[t]{2}{*}{$\mathrm{BS}(0: 8)$} & & -0.000762 & & & & $0.0175 * * *$ & & \\
\hline & & $(0.00253)$ & & & & $(0.00437)$ & & \\
\hline \multirow[t]{2}{*}{$\operatorname{BS}(4: 8)$} & & & -0.000670 & & & & $0.0178 * * *$ & \\
\hline & & & $(0.00260)$ & & & & $(0.00450)$ & \\
\hline \multirow[t]{2}{*}{$\mathrm{BS}(-4: 0)$} & & & & -0.00239 & & & & $0.0142 * * *$ \\
\hline & & & & $(0.00183)$ & & & & $(0.00435)$ \\
\hline Obs. & 317 & 248 & 256 & 307 & 260 & 244 & 252 & 248 \\
\hline$R^{2}$ & 0.138 & 0.105 & 0.141 & 0.143 & 0.459 & 0.491 & 0.504 & 0.420 \\
\hline Period & $Y_{1}$ & $Y_{1}$ & $Y_{1}$ & $Y_{1}$ & $Y_{2}$ & $Y_{2}$ & $Y_{2}$ & $Y_{2}$ \\
\hline
\end{tabular}

Notes: robust standard errors are in parentheses. $* * * p<0.01, * * p<0.05, * p<0.1$. Country fixed effects included in the regressions. Series are in real terms. "BS[0:4]" stands for bond share average value between the peak and 4 quarters after this period. "GDP" is the GDP variation with respect to the GDP peak.

\begin{tabular}{|c|c|c|c|c|c|c|c|c|}
\hline & (1) & (2) & (3) & (4) & (5) & (6) & (7) & (8) \\
\hline \multirow[t]{2}{*}{ B: growth } & GDP & GDP & GDP & GDP & GDP & GDP & GDP & GDP \\
\hline & (OLS) & (OLS) & (OLS) & (OLS) & (OLS) & (OLS) & (OLS) & (OLS) \\
\hline \multirow[t]{2}{*}{$\mathrm{BS}(0: 4)$} & -0.00159 & & & & $0.00843^{* * *}$ & & & \\
\hline & $(0.00167)$ & & & & $(0.00175)$ & & & \\
\hline \multirow[t]{2}{*}{$\mathrm{BS}(0: 8)$} & & -0.00145 & & & & $0.00890 * * *$ & & \\
\hline & & $(0.00184)$ & & & & $(0.00185)$ & & \\
\hline \multirow[t]{2}{*}{$\mathrm{BS}(4: 8)$} & & & -0.00148 & & & & $0.00906 * * *$ & \\
\hline & & & $(0.00189)$ & & & & $(0.00191)$ & \\
\hline \multirow[t]{2}{*}{$\mathrm{BS}(-4: 0)$} & & & & -0.00199 & & & & $0.00865^{* * *}$ \\
\hline & & & & $(0.00149)$ & & & & $(0.00169)$ \\
\hline Obs. & 317 & 248 & 256 & 307 & 260 & 244 & 252 & 248 \\
\hline$R^{2}$ & 0.085 & 0.087 & 0.115 & 0.080 & 0.447 & 0.450 & 0.442 & 0.447 \\
\hline Period & $Y_{1}$ & $Y_{1}$ & $Y_{1}$ & $Y_{1}$ & $Y_{2}$ & $Y_{2}$ & $Y_{2}$ & $Y_{2}$ \\
\hline
\end{tabular}

Notes: robust standard errors are in parentheses. *** $\mathrm{p}<0.01,{ }^{* *} \mathrm{p}<0.05, * \mathrm{p}<0.1$. Country fixed effects included in the regressions. Series are in real terms. "BS[0:4]" stands for bond share average value between the peak and 4 quarters after this period. "GDP" is the GDP quarterly growth. 
Table A.9 - Amplitude of GDP growth w.r. to bond share levels demeaned (RC)

\begin{tabular}{lcccc|cccc}
\hline \hline A: peak & $(1)$ & $(2)$ & $(3)$ & $(4)$ & $(5)$ & $(6)$ & $(7)$ & $(8)$ \\
& GDP & GDP & GDP & GDP & GDP & GDP & GDP & $\begin{array}{c}\text { GDP } \\
(\mathrm{OLS})\end{array}$ \\
& $(\mathrm{OLS})$ & $(\mathrm{OLS})$ & $(\mathrm{OLS})$ & $(\mathrm{OLS})$ & $(\mathrm{OLS})$ & $(\mathrm{OLS})$ & $(\mathrm{OLS})$ \\
\hline $\mathrm{BS}(0: 4)$ & -0.00259 & & & & $0.0127^{* * *}$ & & & \\
& $(0.00232)$ & & & & $(0.00463)$ & & & \\
$\mathrm{BS}(0: 8)$ & & -0.00216 & & & & $0.0139^{* * *}$ & & \\
& & $(0.00253)$ & & & & $(0.00481)$ & & \\
$\mathrm{BS}(4: 8)$ & & & -0.00237 & & & & $0.0135^{* * *}$ & \\
& & & $(0.00260)$ & & & & $(0.00502)$ & \\
$\mathrm{BS}(-4: 0)$ & & & & -0.00261 & & & & $0.0133^{* * *}$ \\
& & & & $(0.00189)$ & & & & $0.00460)$ \\
Obs. & 289 & 224 & 232 & 275 & 235 & 220 & 228 & 219 \\
$R^{2}$ & 0.147 & 0.113 & 0.149 & 0.149 & 0.429 & 0.466 & 0.477 & 0.414 \\
\hline Period & $Y_{1}$ & $Y_{1}$ & $Y_{1}$ & $Y_{1}$ & $Y_{2}$ & $Y_{2}$ & $Y_{2}$ & $Y_{2}$ \\
\hline
\end{tabular}

Notes: robust standard errors are in parentheses. ${ }^{* * *} \mathrm{p}<0.01,{ }^{* *} \mathrm{p}<0.05, * \mathrm{p}<0.1$. Country fixed effects included in the regressions. Series are in real terms. "BS[0:4]" stands for bond share average value between the peak and 4 quarters after this period. Bond share variables are demeaned (average value of the panel for each date). "GDP" is the GDP variation with respect to the GDP peak.

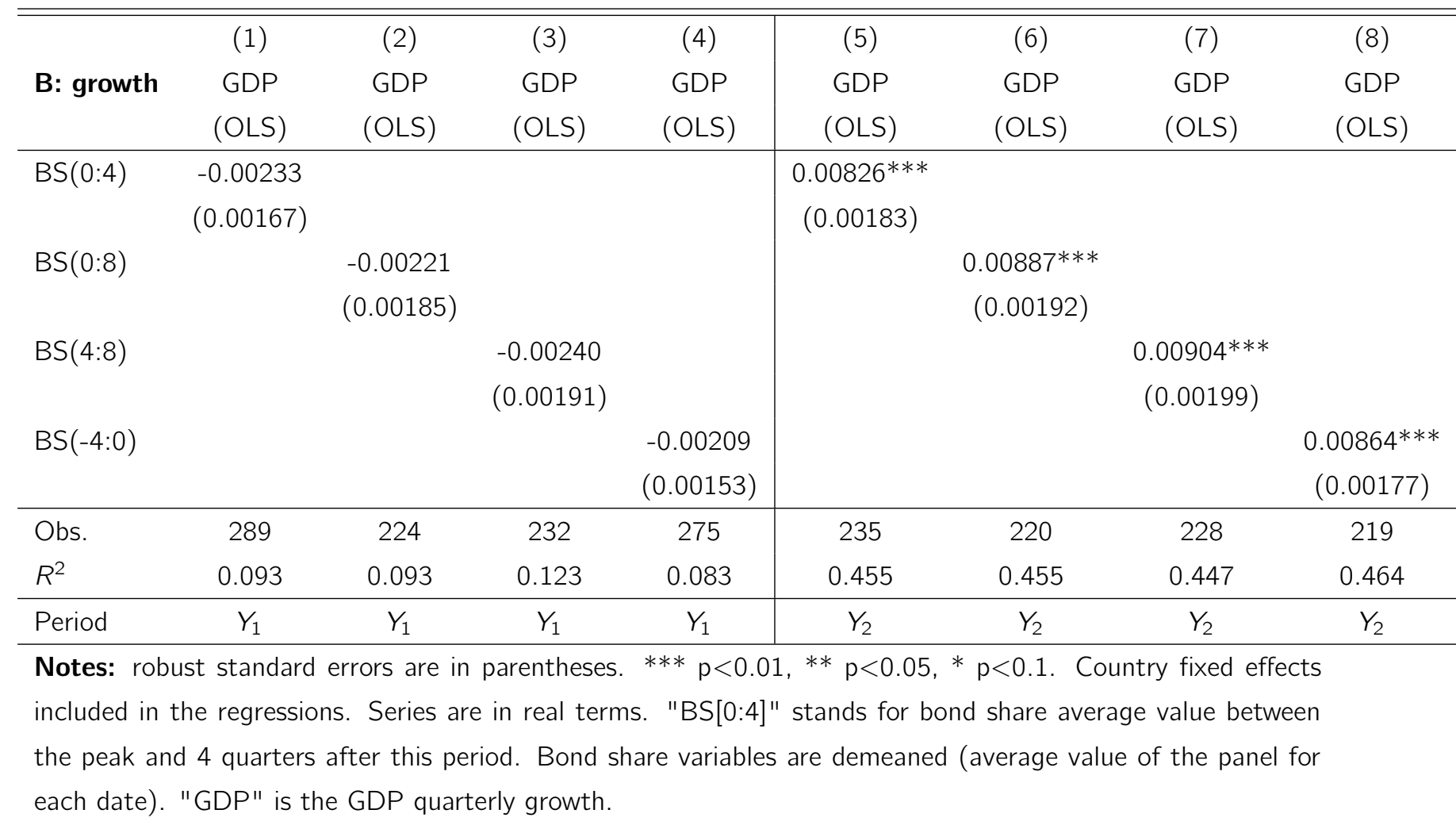


Table A.10 - Duration of recessions and recoveries

\begin{tabular}{lcccccc}
\hline \hline & $\begin{array}{c}(1) \\
\text { p. to t. } \\
\text { (OLS) }\end{array}$ & $\begin{array}{c}\text { t. to } 0 \\
\text { (OLS) }\end{array}$ & $\begin{array}{c}\text { p. to 0 } \\
\text { (OLS) }\end{array}$ & $\begin{array}{c}\text { p. to t. } \\
\text { (OLS) }\end{array}$ & $\begin{array}{c}\text { t. to 0 } \\
\text { (OLS) }\end{array}$ & $\begin{array}{c}\text { p. to 0 } \\
\text { (OLS) }\end{array}$ \\
\hline Bond share[0] & 0.0806 & $-2.258^{* * *}$ & $-2.918^{* * *}$ & & & \\
& $(0.540)$ & $(0.513)$ & $(0.696)$ & & & \\
Bond share & & & & -0.150 & $-3.490^{* * *}$ & $-4.257^{* * *}$ \\
& & & & $(0.531)$ & $(0.944)$ & $(1.300)$ \\
\hline Observations & 76 & 48 & 50 & 80 & 49 & 51 \\
$R^{2}$ & 0.296 & 0.671 & 0.722 & 0.324 & 0.633 & 0.683 \\
\hline
\end{tabular}

Notes: Standard errors are in parentheses. ${ }^{* * *} p<0.01, * * p<0.05, * p<0.1$. Country fixed effects included in the regressions. "p. to t." stands for "peak to trough". "t. to $0 "$ indicates the period between the trough and the recovery to the initial level.

Table A.11 - Amplitude of GDP growth w.r. to bond share : periods after a TROUGH

\begin{tabular}{|c|c|c|c|c|c|c|}
\hline & (1) & (2) & (3) & (4) & (5) & (6) \\
\hline & GDP & GDP & GDP & GDP & GDP & GDP \\
\hline & (OLS) & (OLS) & (OLS) & (OLS) & (OLS) & (OLS) \\
\hline \multirow[t]{2}{*}{ Bond share[0] } & $0.0122 * * *$ & $0.0136 * * *$ & $0.0106^{* * *}$ & $0.0118 * * *$ & $0.0140^{* * *}$ & $0.0167^{* * *}$ \\
\hline & $(0.00377)$ & $(0.00365)$ & $(0.00396)$ & $(0.00401)$ & $(0.00468)$ & $(0.00459)$ \\
\hline \multirow[t]{2}{*}{ Bond share(gr.wr.0) } & & & $0.0200 * *$ & $0.0144 * *$ & 0.0139* & 0.00977 \\
\hline & & & $(0.00834)$ & $(0.00699)$ & $(0.00748)$ & $(0.00673)$ \\
\hline \multirow[t]{2}{*}{ Total credit/GDP[0] } & & & $-0.0495 * * *$ & $-0.0532 * * *$ & -0.0156 & -0.0136 \\
\hline & & & $(0.0111)$ & $(0.00949)$ & $(0.0146)$ & $(0.0140)$ \\
\hline \multirow[t]{2}{*}{ Market cap.[0] } & & & $0.0202^{* * *}$ & $0.0200 * * *$ & $0.0198^{* * *}$ & $0.0177^{* * *}$ \\
\hline & & & $(0.00495)$ & $(0.00416)$ & $(0.00437)$ & $(0.00376)$ \\
\hline \multirow[t]{2}{*}{ Total credit/GDP[gr.DM,0] } & & & $-0.175^{* * *}$ & $-0.143^{* * *}$ & -0.0441 & -0.0280 \\
\hline & & & $(0.0563)$ & $(0.0501)$ & $(0.0539)$ & $(0.0494)$ \\
\hline \multirow[t]{2}{*}{ House prices[0] } & & & & & $-0.0497 * * *$ & $-0.0492 * * *$ \\
\hline & & & & & $(0.00955)$ & $(0.00969)$ \\
\hline \multirow[t]{2}{*}{ Total credit(growth) } & & & & & $0.226^{*}$ & $0.251^{* * *}$ \\
\hline & & & & & $(0.118)$ & $(0.0639)$ \\
\hline \multirow[t]{2}{*}{ House Prices(growth) } & & & & & $0.102^{* *}$ & $0.0948 * * *$ \\
\hline & & & & & $(0.0471)$ & $(0.0266)$ \\
\hline Observations & 287 & 413 & 165 & 237 & 126 & 183 \\
\hline$R^{2}$ & 0.402 & 0.365 & 0.580 & 0.543 & 0.780 & 0.707 \\
\hline Period & $T+4$ & $T+6$ & $T+4$ & $T+6$ & $T+4$ & $T+6$ \\
\hline
\end{tabular}

Notes: robust standard errors are in parentheses. ${ }^{* * *} \mathrm{p}<0.01,{ }^{* *} \mathrm{p}<0.05,{ }^{*} \mathrm{p}<0.1$. Country fixed effects included in the regressions. Periods are defined after a trough. " $T+4$ " stands for the period between a Trough and 4 quarters after. "[0]" is defined as the peak level. GDP is defined as a variation relative to GDP peak. 
Table A.12 - Amplitude of Investment depending on financial structures

\begin{tabular}{|c|c|c|c|c|c|c|}
\hline & (1) & (2) & (3) & (4) & (5) & (6) \\
\hline & I & I & I & I & I & I \\
\hline & (OLS) & (OLS) & (OLS) & (OLS) & (OLS) & (OLS) \\
\hline \multirow[t]{2}{*}{ Bond share[0] } & -0.0135 & $0.0238 * *$ & $-0.0136^{*}$ & $0.0207 * *$ & -0.00980 & $0.0355 * * *$ \\
\hline & $(0.00833)$ & $(0.0111)$ & $(0.00827)$ & $(0.0105)$ & $(0.00930)$ & $(0.0115)$ \\
\hline \multirow[t]{2}{*}{ Bond share[gr.wr.0] } & $0.0948 * * *$ & $0.0875^{* * *}$ & $0.0970 * * *$ & $0.0846 * * *$ & $0.143 * * *$ & $0.0946 * * *$ \\
\hline & $(0.0312)$ & $(0.0233)$ & $(0.0315)$ & $(0.0235)$ & $(0.0504)$ & $(0.0261)$ \\
\hline \multirow[t]{2}{*}{ Total credit/GDP[0] } & & & -0.00637 & $-0.0718 * * *$ & $-0.0505 * * *$ & $-0.0946 * *$ \\
\hline & & & $(0.0114)$ & $(0.0222)$ & $(0.0193)$ & $(0.0389)$ \\
\hline \multirow[t]{2}{*}{ Market cap.[0] } & & & & & $0.0419 * * *$ & $0.0547^{* * *}$ \\
\hline & & & & & $(0.00898)$ & $(0.0196)$ \\
\hline Observations & 281 & 228 & 281 & 228 & 172 & 146 \\
\hline$R^{2}$ & 0.334 & 0.429 & 0.335 & 0.455 & 0.415 & 0.540 \\
\hline Period & $Y_{1}$ & $Y_{2}$ & $Y_{1}$ & $Y_{2}$ & $Y_{1}$ & $Y_{2}$ \\
\hline \multicolumn{7}{|c|}{$\begin{array}{l}\text { Notes: robust standard errors are in parentheses. }{ }^{* *} \mathrm{p}<0.01,{ }^{* *} \mathrm{p}<0.05, * \mathrm{p}<0.1 \text {. Country fixed effects } \\
\text { included in the regressions. "I" means investment. "Market cap." is market capitalization. "[0]" is the peak } \\
\text { period. "[gr.wr.0]" measures growth with respect to the peak period. Variations of investment with respect } \\
\text { to the GDP peak quarter. }\end{array}$} \\
\hline
\end{tabular}

Table A.13 - Bank crisis

\begin{tabular}{lcccc}
\hline \hline & $(1)$ & $(2)$ & $(3)$ & $(4)$ \\
& GDP & GDP & GDP & GDP \\
& $(\mathrm{OLS})$ & $(\mathrm{OLS})$ & $(\mathrm{OLS})$ & $(\mathrm{OLS})$ \\
\hline Bond share[0] & -0.00304 & $0.0157^{* * *}$ & -0.00359 & $0.0114^{* *}$ \\
& $(0.00255)$ & $(0.00433)$ & $(0.00290)$ & $(0.00484)$ \\
Bond share(gr.wr.0) & 0.0194 & $0.0272^{* * *}$ & 0.0188 & $0.0278^{* * *}$ \\
& $(0.0157)$ & $(0.00766)$ & $(0.0158)$ & $(0.00782)$ \\
Bank crisis & $-0.00517^{* *}$ & $-0.0199^{* * *}$ & & \\
& $(0.00228)$ & $(0.00447)$ & & \\
Bond share[0]*Bank crisis & & & 0.00122 & $0.00650^{* * *}$ \\
& & & $(0.00104)$ & $(0.00196)$ \\
\hline Observations & 196 & 179 & 196 & 179 \\
$R^{2}$ & 0.114 & 0.590 & 0.107 & 0.574 \\
\hline Period & $Y_{1}$ & $Y_{2}$ & $Y_{1}$ & $Y_{2}$ \\
\hline
\end{tabular}

Notes: robust standard errors are in parentheses. $* * * \mathrm{p}<0.01,{ }^{* *} \mathrm{p}<0.05, *$ $p<0.1$. Country fixed effects included in the regressions. "[0]" is defined as the peak level. GDP is defined as a variation relative to GDP peak. "Bond share(gr.wr.0)" is bond share variation with respect to the peak period. "Bank crisis" is a dummy variable for the presence of banking crisis. 
Table A.14 - Corporate Debt Structure and Firm size

\begin{tabular}{|c|c|c|c|}
\hline & (1) & (2) & (3) \\
\hline & GDP & GDP & GDP \\
\hline & (OLS) & $(\mathrm{OLS})$ & (OLS) \\
\hline \multirow[t]{2}{*}{ Bond share[0] } & & $-0.0287^{* *}$ & $-0.0233^{*}$ \\
\hline & & $(0.0139)$ & $(0.0126)$ \\
\hline \multirow[t]{2}{*}{ Bond share $[0]^{*}$ Large/Small Firms } & & $0.0330 *$ & $0.0329 * *$ \\
\hline & & $(0.0170)$ & $(0.0160)$ \\
\hline \multirow[t]{2}{*}{ Large/Small firms } & $0.128 * * *$ & $0.126 * * *$ & 0.0652 \\
\hline & $(0.0307)$ & $(0.0413)$ & $(0.0452)$ \\
\hline \multirow[t]{2}{*}{ Bond share[gr.0] } & & & $0.0190 * * *$ \\
\hline & & & $(0.00725)$ \\
\hline Observations & 191 & 191 & 191 \\
\hline$R^{2}$ & 0.407 & 0.421 & 0.437 \\
\hline Period & $Y_{2}$ & $Y_{2}$ & $Y_{2}$ \\
\hline \multicolumn{4}{|c|}{$\begin{array}{l}\text { Notes: robust standard errors are in parentheses. *** } \mathrm{p}<0.01, * * \mathrm{p}<0.05 \text {, } \\
* \mathrm{p}<0.1 \text {. Country fixed effects included in the regressions. "[0]" is de- } \\
\text { fined as the peak level. GDP is defined as a variation relative to GDP peak. } \\
\text { "Bond share[gr.0]" is bond share variation with respect to the peak period. } \\
\text { "Large/Small" is the ratio of large firms ( } 250+\text { employees) over small firms (1-49 } \\
\text { employees, value added by size class). }\end{array}$} \\
\hline
\end{tabular}

Table A.15 - Bond share[0] and total credit

\begin{tabular}{|c|c|c|c|c|c|c|}
\hline & (1) & (2) & (3) & (4) & (5) & (6) \\
\hline \multirow[t]{2}{*}{$\mathrm{AC} / \mathrm{AC}[0]$} & $A C$ & $A C$ & $A C$ & $A C$ & $A C$ & $A C$ \\
\hline & $(\mathrm{OLS})$ & (OLS) & $(\mathrm{OLS})$ & (OLS) & $(\mathrm{OLS})$ & $(\mathrm{OLS})$ \\
\hline \multirow[t]{2}{*}{$\mathrm{BS}[0]$} & 0.0336 & $0.135^{* * *}$ & & & & \\
\hline & $(0.0217)$ & $(0.0333)$ & & & & \\
\hline \multirow[t]{2}{*}{$L / L[0]$} & $0.840 * * *$ & $0.742 * * *$ & $0.928 * * *$ & $0.761^{* * *}$ & $1.000 * * *$ & $1.000 * * *$ \\
\hline & $(0.0150)$ & $(0.0180)$ & $(0.0151)$ & $(0.0183)$ & $(6.27 \mathrm{e}-08)$ & $(6.50 \mathrm{e}-08)$ \\
\hline \multirow[t]{2}{*}{$(B / B[0]-L / L[0])$} & & & $0.0822 * * *$ & $0.0106 * * *$ & & \\
\hline & & & $(0.00742)$ & $(0.00204)$ & & \\
\hline \multirow[t]{2}{*}{$\mathrm{BS}[0]^{*}(\mathrm{~B} / \mathrm{B}[0]-\mathrm{L} / \mathrm{L}[0])$} & & & & & $1.000 * * *$ & $1.000 * * *$ \\
\hline & & & & & $(2.01 \mathrm{e}-07)$ & $(1.64 \mathrm{e}-07)$ \\
\hline Observations & 315 & 256 & 315 & 256 & 315 & 256 \\
\hline$R^{2}$ & 0.926 & 0.933 & 0.946 & 0.935 & 1.000 & 1.000 \\
\hline Period & $Y_{1}$ & $Y_{2}$ & $Y_{1}$ & $Y_{2}$ & $Y_{1}$ & $Y_{2}$ \\
\hline
\end{tabular}


Table A.16 - Bank Spread and Bond Spread

\begin{tabular}{|c|c|c|c|c|c|c|}
\hline & $(1)$ & (2) & (3) & (4) & (5) & (6) \\
\hline & Spread(Bond) & Spread(Bank) & GDP & GDP & GDP & GDP \\
\hline & (OLS) & (OLS) & (OLS) & (OLS) & (OLS) & (OLS) \\
\hline \multirow[t]{2}{*}{$Y_{1}$} & $1.466^{* * *}$ & $0.241^{* * *}$ & & & & \\
\hline & $(0.315)$ & $(0.0710)$ & & & & \\
\hline \multirow[t]{2}{*}{$Y_{2}$} & $3.389 * * *$ & $1.223^{* * *}$ & & & & \\
\hline & $(0.393)$ & $(0.0963)$ & & & & \\
\hline \multirow[t]{2}{*}{$Y_{-1}$} & -0.339 & $-0.0883^{*}$ & & & & \\
\hline & $(0.303)$ & $(0.0476)$ & & & & \\
\hline \multirow[t]{2}{*}{$Y_{-2}$} & $-0.459 *$ & $-0.314 * * *$ & & & & \\
\hline & $(0.266)$ & $(0.0568)$ & & & & \\
\hline \multirow[t]{2}{*}{ Spread (Bond) } & & & $-0.0245 * * *$ & $-0.0302 * * *$ & & \\
\hline & & & $(0.00229)$ & $(0.00408)$ & & \\
\hline \multirow[t]{2}{*}{ Spread (Bank) } & & & & & $-0.0352 * * *$ & $-0.0453 * * *$ \\
\hline & & & & & $(0.00328)$ & $(0.00614)$ \\
\hline Observations & 304 & 207 & 88 & 68 & 56 & 45 \\
\hline$R^{2}$ & 0.446 & 0.682 & 0.641 & 0.476 & 0.699 & 0.922 \\
\hline Period & & & $Y_{1}$ & $Y_{2}$ & $Y_{1}$ & $Y_{2}$ \\
\hline
\end{tabular}

Notes: robust standard errors are in parentheses. ${ }^{* * *} \mathrm{p}<0.01,{ }^{* *} \mathrm{p}<0.05,{ }^{*} \mathrm{p}<0.1$. Country fixed effects included in the regressions. Spread(Bond) is the spread between the bond interest rate and the short-term interest rate. Spread(Bank) is the spread between the bank lending interest rate and the short-term interest rate. GDP is measured with respect to its level during the GDP peak period. 


\section{B. Additional Figures}

Figure B.1 - GDP, Bonds and Loans over the cycle (year-to-year growth)
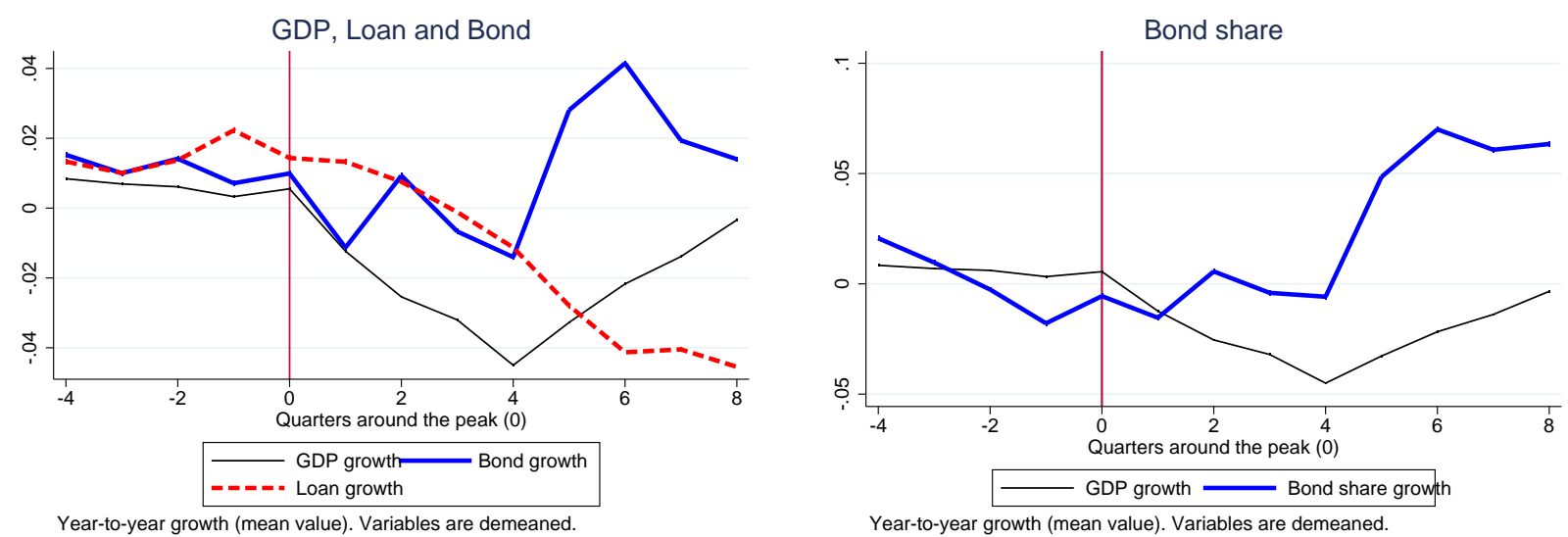

Figure B.2 - Recoveries depending on Bond share level

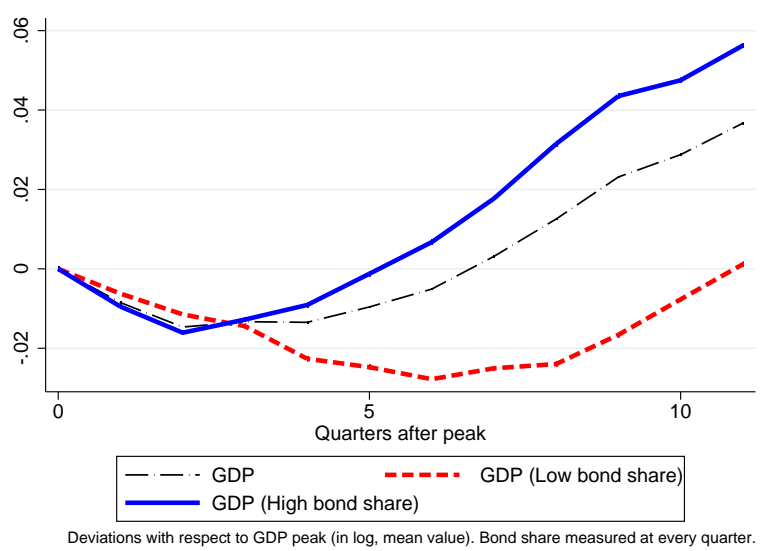


Figure B.3 - Investment recoveries depending on financial structures

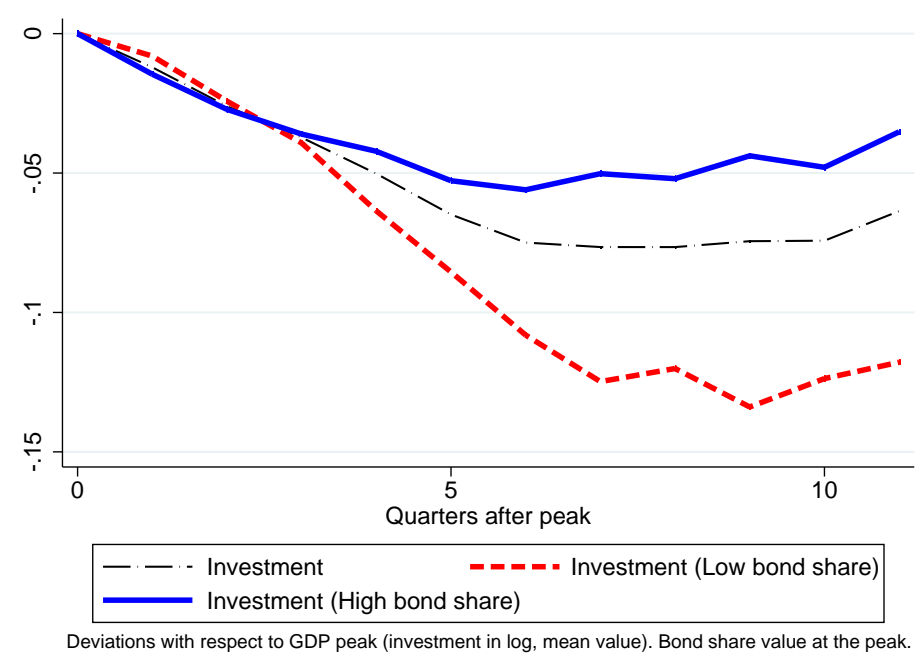

Figure B.4 - Recoveries and Bank Crisis

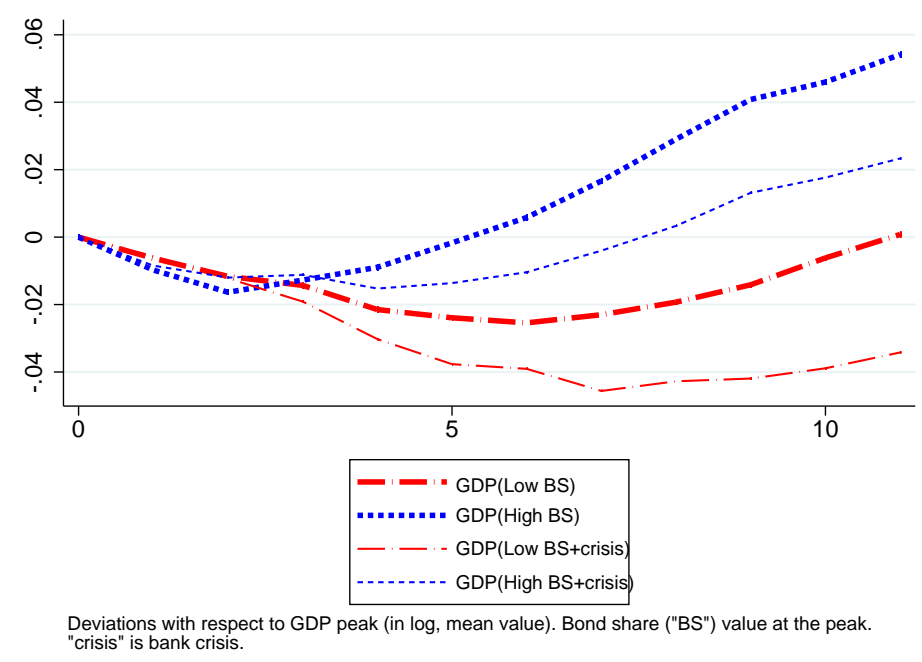


Figure B.5 - Bond surplus during recovery

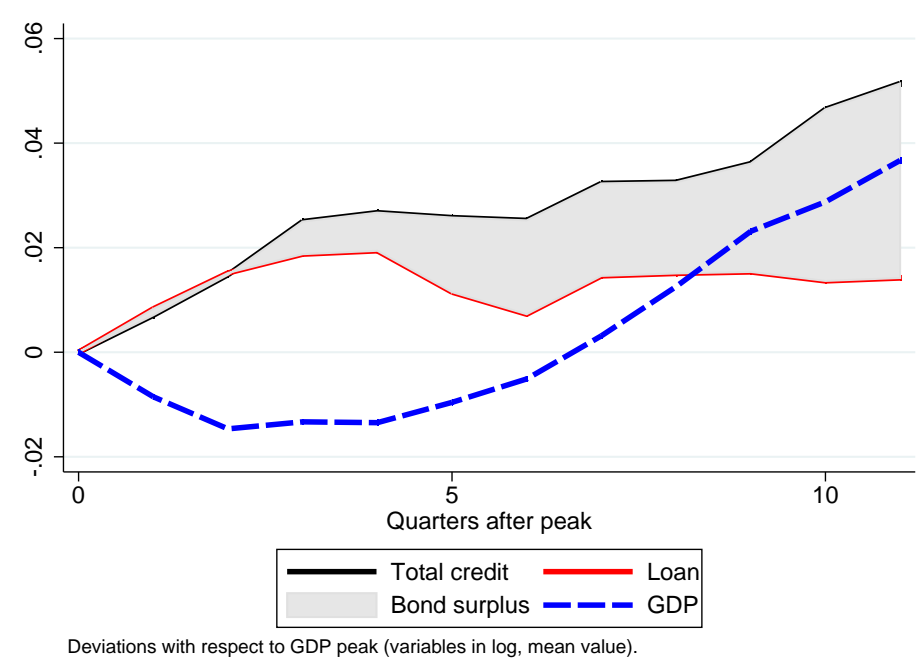

Figure B.6 - Bank Spread and Bond Spread

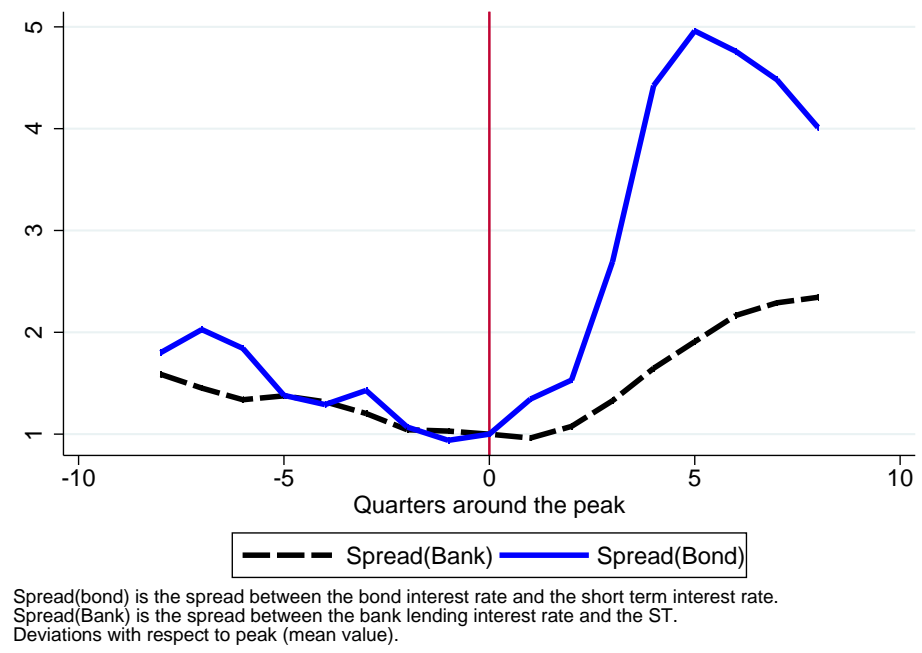




\section{Model}

This section presents our extension of the model developed by Adrian et al. (2012), hereafter referred to as ACS.

\section{Bank Credit Supply}

The project $j$ financed by the bank as of time succeeds when $Z_{j t}>0$, where $Z_{j t}$ is the random variable

$$
Z_{j t}=-\Phi^{-1}\left(\varepsilon_{t}\right)+\sqrt{\rho} Z_{t}+\sqrt{1-\rho} X_{j}
$$

where $\Phi(\cdot)$ is the c.d.f. of the standard normal, $z_{t}$ and $X_{j}$ two independent standard normals, and $\rho \in[0,1]$ a constant. The probability of default is $\operatorname{Pr}\left(Z_{j t}\right)<0$, then using (C.1)

$$
\operatorname{Pr}\left(Z_{j t}\right)=\operatorname{Pr}\left(\sqrt{\rho} z_{t}+\sqrt{1-\rho} X_{j}<\Phi^{-1}\left(\varepsilon_{t}\right)\right)
$$

where $\left(\sqrt{\rho} z_{t}+\sqrt{1-\rho} X_{j}\right)$ is normally distributed, hence

$$
\operatorname{Pr}\left(Z_{j t}\right)=\Phi\left(\Phi^{-1}\left(\varepsilon_{t}\right)\right)=\varepsilon_{t}
$$

The probability reduces to the structural parameter $\varepsilon_{t}$. The value of bank assets as of time $t$ are

$$
w\left(z_{t}\right)=\left(1+r_{t}\right) C_{t}^{B} \operatorname{Pr}\left(Z_{j t}>0\right)
$$

where $\operatorname{Pr}\left(Z_{j t}>0\right)$ is the no-defaulting probability. Given the definition (C.1), it becomes

$$
\begin{aligned}
w\left(z_{t}\right) & =\left(1+r_{t}\right) C_{t}^{B} \operatorname{Pr}\left(\sqrt{\rho} z_{t}+\sqrt{1-\rho} X_{j}>\Phi^{-1}\left(\varepsilon_{t}\right)\right) \\
& =\left(1+r_{t}\right) C_{t}^{B} \operatorname{Pr}\left(\frac{\sqrt{\rho} z_{t}-\Phi^{-1}\left(\varepsilon_{t}\right)}{\sqrt{1-\rho}}>X_{j}\right)
\end{aligned}
$$

where $X_{j}$ is normally distributed, then it is finally

$$
w\left(z_{t}\right)=\left(1+r_{t}\right) C_{t}^{B} \Phi\left(\frac{\sqrt{\rho} z_{t}-\Phi^{-1}\left(\varepsilon_{t}\right)}{\sqrt{1-\rho}}\right)
$$

The expected bank earnings/losses are

$$
\begin{aligned}
\Pi_{t} & =w\left(z_{t}\right)-(1+f) L_{t} \\
& =\left(1+r_{t}\right) C_{t}^{B} \Phi\left(\frac{\sqrt{\rho} z_{t}-\Phi^{-1}\left(\varepsilon_{t}\right)}{\sqrt{1-\rho}}\right)-(1+f) L_{t}
\end{aligned}
$$

It is useful for the remainder to compute the inverse function of $w\left(z_{t}\right)$ as

$$
z_{t}=w^{-1}\left(w_{t}\right)=\frac{\Phi^{-1}\left(\varepsilon_{t}\right)+\sqrt{1-\rho} \Phi^{-1}\left(\frac{w_{t}}{\left(1+r_{t}\right) C_{t}^{B}}\right)}{\sqrt{\rho}}
$$


and the c.d.f. of $w\left(z_{t}\right)$ as

$$
\begin{aligned}
F(z) & =\operatorname{Pr}\left(w_{t}\left(z_{t}\right) \leq z\right) \\
& =\operatorname{Pr}\left(z_{t} \leq w^{-1}\left(z_{t}\right)\right) \\
& =\Phi\left(\frac{\Phi^{-1}\left(\varepsilon_{t}\right)+\sqrt{1-\rho} \Phi^{-1}\left(\frac{z_{t}}{\left(1+r_{t}\right) C_{t}^{B}}\right)}{\sqrt{\rho}}\right)
\end{aligned}
$$

which is the probability that bank assets are below the $z$-value.

The bank chooses $C_{t}^{B}$ so as to verify the $\mathrm{VaR}$ constraint (and not to maximize intertemporal profits): $\operatorname{Pr}\left(w_{t} \leq(1+f) L_{t}\right)=\alpha$. Therefore,

$$
\operatorname{Pr}\left(w_{t} \leq(1+f) L\right)=\Phi\left(\frac{\Phi^{-1}\left(\varepsilon_{t}\right)+\sqrt{1-\rho} \Phi^{-1}\left(\frac{(1+f) L_{t}}{\left(1+r_{t}\right) C_{t}^{B}}\right)}{\sqrt{\rho}}\right)=\alpha
$$

or equivalently

$$
\frac{(1+f) L_{t}}{\left(1+r_{t}\right) C_{t}^{B}}=\Phi\left(\frac{\sqrt{\rho} \Phi^{-1}(\alpha)-\Phi^{-1}\left(\varepsilon_{t}\right)}{\sqrt{1-\rho}}\right) \equiv \varphi\left(\alpha, \varepsilon_{t}, \rho\right)
$$

since

$$
\Phi^{-1}\left(\Phi\left(\frac{\Phi^{-1}\left(\varepsilon_{t}\right)+\sqrt{1-\rho} \Phi^{-1}\left(\frac{(1+f) L_{t}}{\left(1+r_{t}\right) C_{t}^{B}}\right)}{\sqrt{\rho}}\right)\right)=\Phi^{-1}(\alpha)
$$

We deduce from (C.8), the bank debt demand

$$
(1+f) L_{t}=\varphi\left(\alpha, \varepsilon_{t}, \rho\right)\left(1+r_{t}\right) C_{t}^{B}
$$

For the bank debt demand (C.9), profits defined by (C.6) become

$$
\begin{aligned}
\Pi_{t} & =\left[\Phi\left(\frac{\sqrt{\rho} z_{t}-\Phi^{-1}\left(\varepsilon_{t}\right)}{\sqrt{1-\rho}}\right)-\Phi\left(\frac{\sqrt{\rho} \Phi^{-1}(\alpha)-\Phi^{-1}\left(\varepsilon_{t}\right)}{\sqrt{1-\rho}}\right)\right]\left(1+r_{t}\right) C_{t}^{B}(C \\
& =\psi\left(\alpha, \varepsilon_{t}, z_{t}, \rho\right)\left(1+r_{t}\right) C_{t}^{B}
\end{aligned}
$$

We assume $z_{1}<\Phi^{-1}(\alpha)$ to verify $\Pi<0$ in $(7)$.

Because of financial losses during the recession, the credit supply is different for the normal and recession periods $t=\{0,1\}$ than for the recovery period $t=2$. In period $t=\{0,1\}$, the situation corresponds exactly to the case considered by ACS. Since the bank capital is fixed to $E_{t}=E$ for $t=\{0,1\}$, the bank credit supply is

$$
C_{t}^{B}=E_{t}+\varphi\left(\alpha, \varepsilon_{t}, \rho\right)\left(\frac{1+r_{t}}{1+f}\right) C_{t}^{B}
$$


or equivalently

$$
C_{t}^{B}=\frac{E}{1-\varphi\left(\alpha, \varepsilon_{t}, \rho\right)\left(1+r_{t}\right) /(1+f)}
$$

where bank capital is $E_{t}=E$ because $D_{t-1}=\Pi_{t-1}$ for $t=\{0,1\}-$ see (7). The reduction in bank credit supply during the recession is given by the ratio

$$
\frac{C_{1}^{B}}{C_{0}^{B}}=\frac{1-\varphi\left(\alpha, \varepsilon_{0}, \rho\right)\left(1+r_{0}\right) /(1+f)}{1-\varphi\left(\alpha, \varepsilon_{1}, \rho\right)\left(1+r_{1}\right) /(1+f)}
$$

which is below the unity since $\varepsilon_{1}>\varepsilon_{0}$ implies $\varphi\left(\alpha, \varepsilon_{1}, \rho\right)<\varphi\left(\alpha, \varepsilon_{0}, \rho\right)$.

The decision in period $t=2$ is impacted by the bank losses during the recession. The balance sheet of banks is

$$
C_{2}^{B}=E+L_{2}+\Pi_{1}
$$

using (C.9), the bank credit supply is

$$
C_{2}^{B}=E+\varphi\left(\alpha, \varepsilon_{2}, \rho\right)\left(\frac{1+r_{2}}{1+f}\right) C_{2}^{B}+\Pi_{1}
$$

using (C.10), it becomes

$$
C_{2}^{B}=\frac{E+\psi\left(\alpha, \varepsilon_{1}, z_{1}, \rho\right)\left(1+r_{1}\right) C_{1}^{B}}{1-\varphi\left(\alpha, \varepsilon_{2}, \rho\right)\left(1+r_{2}\right) /(1+f)}
$$

using (C.12), it becomes

$$
C_{2}^{B}=\frac{E}{1-\varphi\left(\alpha, \varepsilon_{2}, \rho\right)\left(1+r_{2}\right) /(1+f)}\left[1+\frac{\psi\left(\alpha, \varepsilon_{1}, z_{1}, \rho\right)\left(1+r_{1}\right)}{1-\varphi\left(\alpha, \varepsilon_{1}, \rho\right)\left(1+r_{1}\right) /(1+f)}\right]
$$

When compared with the regular period $(t=0)$, the credit ratio is

$$
\frac{C_{2}^{B}}{C_{0}^{B}}=\frac{1-\varphi\left(\alpha, \varepsilon_{0}, \rho\right)\left(1+r_{0}\right) /(1+f)}{1-\varphi\left(\alpha, \varepsilon_{2}, \rho\right)\left(1+r_{2}\right) /(1+f)} \underbrace{\left[1+\frac{\psi\left(\alpha, \varepsilon_{1}, z_{1}, \rho\right)\left(1+r_{1}\right)}{1-\varphi\left(\alpha, \varepsilon_{1}, \rho\right)\left(1+r_{1}\right) /(1+f)}\right]}_{<1}
$$

which is below unity because $\psi\left(\alpha, \varepsilon_{1}, z_{1}, \rho\right)<0,1>\varphi\left(\alpha, \varepsilon_{1}, \rho\right)\left(1+r_{1}\right) /(1+f), \varepsilon_{2}=$ $\varepsilon_{0}$, and if $r_{2}>r_{0}$. Without losses during the recession, $\psi\left(\alpha, \varepsilon_{1}, z_{1}, \rho\right)=0$, the bank credit supply would recover the pre-recession expression because the fundamentals are the same in $t=\{0,2\}: \varepsilon_{0}=\varepsilon_{2}$. When compared with the recession period $(t=1)$, the credit ratio is

$$
\frac{C_{2}^{B}}{C_{1}^{B}}=\underbrace{\frac{1-\varphi\left(\alpha, \varepsilon_{1}, \rho\right)\left(1+r_{1}\right) /(1+f)}{1-\varphi\left(\alpha, \varepsilon_{2}, \rho\right)\left(1+r_{2}\right) /(1+f)}}_{>1, \text { reduction in risk }} \underbrace{\left[1+\frac{\psi\left(\alpha, \varepsilon_{1}, z_{1}, \rho\right)\left(1+r_{1}\right)}{1-\varphi\left(\alpha, \varepsilon_{1}, \rho\right)\left(1+r_{1}\right) /(1+f)}\right]}_{<1, \text { financial losses }}
$$

Depending on the size of financial losses, bank credit may fall once again in the recovery or not. 
To sum up, the bank supply is

$$
C_{t}^{B}=\frac{E}{1-\varphi\left(\alpha, \varepsilon_{t}, \rho\right)\left(1+r_{t}\right) /(1+f)}\left[1+\mathbf{1}_{t} \times \frac{\psi\left(\alpha, \varepsilon_{t-1}, z_{1}, \rho\right)\left(1+r_{t-1}\right)}{1-\varphi\left(\alpha, \varepsilon_{t-1}, \rho\right)\left(1+r_{t-1}\right) /(1+f)}\right]
$$

where $\mathbf{1}_{t}=1$ if $t=2$ and $\mathbf{1}_{t}=0$ otherwise.

\section{Direct Credit}

This section is unchanged with respect to ACS, we simply implement our time convention to define the direct credit provided by households $C_{t}^{H}$ as

$$
C_{t}^{H}=\frac{T\left[\left(1-\varepsilon_{t}\right)\left(1+r_{t}\right)-1\right]}{\sigma_{t}^{2}\left(1+r_{t}\right)^{2}}
$$

where

$$
\sigma_{t}^{2}=\Phi_{2}\left(\Phi^{-1}\left(\varepsilon_{t}\right), \Phi^{-1}\left(\varepsilon_{t}\right) ; \rho\right)-\varepsilon_{t}^{2}
$$

\section{Comparative Statistics of Credit Supply}

The risk premium is

$$
\pi_{t}=\left(1-\varepsilon_{t}\right)\left(1+r_{t}\right)-1
$$

We use the credit supply (C.20) to get the following expression for $\left(1+r_{t}\right)$, first

$$
\frac{C_{t}^{B}}{E}\left[1-\varphi\left(\alpha, \varepsilon_{t}, \rho\right)\left(1+r_{t}\right) /(1+f)\right]=\left[1+\mathbf{1}_{t} \times \frac{\psi\left(\alpha, \varepsilon_{t-1}, z_{1}, \rho\right)\left(1+r_{t-1}\right)}{1-\varphi\left(\alpha, \varepsilon_{t-1}, \rho\right)\left(1+r_{t-1}\right) /(1+f)}\right]
$$

then,

$$
1-\varphi\left(\alpha, \varepsilon_{t}, \rho\right)\left(1+r_{t}\right) /(1+f)=\frac{E}{C_{t}^{B}}\left[1+\mathbf{1}_{t} \times \frac{\psi\left(\alpha, \varepsilon_{t-1}, z_{1}, \rho\right)\left(1+r_{t-1}\right)}{1-\varphi\left(\alpha, \varepsilon_{t-1}, \rho\right)\left(1+r_{t-1}\right) /(1+f)}\right]
$$

then,

$$
-\varphi\left(\alpha, \varepsilon_{t}, \rho\right)\left(1+r_{t}\right) /(1+f)=-1+\frac{E}{C_{t}^{B}}\left[1+\mathbf{1}_{t} \times \frac{\psi\left(\alpha, \varepsilon_{t-1}, z_{1}, \rho\right)\left(1+r_{t-1}\right)}{1-\varphi\left(\alpha, \varepsilon_{t-1}, \rho\right)\left(1+r_{t-1}\right) /(1+f)}\right]
$$

then,

$$
\left(1+r_{t}\right)=\frac{(1+f)}{\varphi\left(\alpha, \varepsilon_{t}, \rho\right)}\left[1-\frac{E}{C_{t}^{B}}\left(1+\mathbf{1}_{t} \times \frac{\psi\left(\alpha, \varepsilon_{t-1}, z_{1}, \rho\right)\left(1+r_{t-1}\right)}{1-\varphi\left(\alpha, \varepsilon_{t-1}, \rho\right)\left(1+r_{t-1}\right) /(1+f)}\right)\right]
$$

where $\mathbf{1}_{t}=1$ if $t=2$ and $\mathbf{1}_{t}=0$ otherwise. Then, the risk premium (C.23) consistent with bank supply of credit becomes

$$
\pi_{t}^{B}=\left(1-\varepsilon_{t}\right) \frac{(1+f)}{\varphi\left(\alpha, \varepsilon_{t}, \rho\right)}\left[1-\frac{E}{C_{t}^{B}}\left(1+\mathbf{1}_{t} \times \frac{\psi\left(\alpha, \varepsilon_{t-1}, z_{1}, \rho\right)\left(1+r_{t-1}\right)}{1-\varphi\left(\alpha, \varepsilon_{t-1}, \rho\right)\left(1+r_{t-1}\right) /(1+f)}\right)\right]-1
$$


Equation (14) of ACS correponds to the case $\mathbf{1}_{t}=0$.

Introducing the risk premium definition (C.23) into the equation of credit supply for households gives

$$
C_{t}^{H}=\frac{T\left[\left(1-\varepsilon_{t}\right)\left(\frac{1+\pi_{t}}{1-\varepsilon_{t}}\right)-1\right]}{\sigma_{t}^{2}\left[\frac{\left(1+\pi_{t}\right)}{\left(1-\varepsilon_{t}\right)}\right]^{2}}
$$

since

$$
\left(1+r_{t}\right)=\left(\frac{1+\pi_{t}}{1-\varepsilon_{t}}\right)
$$

then

$$
C_{t}^{H}=\frac{T \pi_{t}}{\sigma_{t}^{2} \frac{\left(1+\pi_{t}\right)^{2}}{\left(1-\varepsilon_{t}\right)^{2}}}
$$

then

$$
\frac{C_{t}^{H} \sigma_{t}^{2}}{T\left(1-\varepsilon_{t}\right)^{2}}\left(1+\pi_{t}\right)^{2}-\left(1+\pi_{t}\right)+1=0
$$

Then, the risk premium (C.23) consistent with household supply of credit is

$$
\pi^{H}\left(\varepsilon_{t}\right)=\frac{1-\sqrt{1-4 C_{t}^{H} \sigma_{t}^{2} /\left[T\left(1-\varepsilon_{t}\right)^{2}\right]}}{2 C_{t}^{H} \sigma_{t}^{2} /\left[T\left(1-\varepsilon_{t}\right)^{2}\right]}-1
$$

\section{Market Equilibrium}

$$
C_{t}^{B}+C_{t}^{H}=C_{t}^{D}
$$

therefore

$$
\begin{aligned}
& C_{t}^{D}=C_{t}^{H}+ \\
& \frac{E}{1-\varphi\left(\alpha, \varepsilon_{t}, \rho\right)\left(1+\pi_{t}\right) /\left[\left(1-\varepsilon_{t}\right)(1+f)\right]}\left[1+\mathbf{1}_{t} \times \frac{\psi\left(\alpha, \varepsilon_{t-1}, z_{1}, \rho\right)\left(1+r_{t-1}\right)}{1-\varphi\left(\alpha, \varepsilon_{t-1}, \rho\right)\left(1+r_{t-1}\right) /(1+f)}\right] \\
& \text { using (C.23) to get }\left(1+r_{t}\right)=\left(1+\pi_{t}\right) /\left(1-\varepsilon_{t}\right) .
\end{aligned}
$$

Assuming

$$
C^{D}\left(\pi_{t}\right)=\underline{d}+\bar{d} \pi_{t}^{\delta}
$$

with $\delta<0$ and

$$
\frac{d C^{D}\left(\pi_{t}\right)}{d \pi_{t}} \frac{\pi_{t}}{C^{D}\left(\pi_{t}\right)}=\delta \frac{\bar{d} \pi_{t}^{\delta}}{\underline{d}+\bar{D} \pi_{t}^{\delta}}
$$

without fixed credit demand (eg $\underline{d}=0$ ), $\delta$ is the elasticity of the credit demand function. To solve the model:

1. Calibration of the structural parameters 
2. For $t=\{0,1\}, \pi_{t}$ solves

$$
\frac{E}{1-\varphi\left(\alpha, \varepsilon_{t}, \rho\right) \frac{\left(1+\pi_{t}\right)}{\left(1-\varepsilon_{t}\right)(1+f)}}+T \frac{\left(1-\varepsilon_{t}\right)^{2} \pi_{t}}{\sigma_{t}^{2}\left(1+\pi_{t}\right)^{2}}=C^{D}\left(\pi_{t}\right)
$$

given the realized value $\varepsilon_{t}$. For $t=1$, compute

$$
\lambda\left(\alpha, \varepsilon_{1}, z_{1}, \rho, \pi_{1}, f\right)=1+\frac{\psi\left(\alpha, \varepsilon_{1}, z_{1}, \rho\right)\left(1+\pi_{1}\right) /\left(1-\varepsilon_{1}\right)}{1-\varphi\left(\alpha, \varepsilon_{1}, \rho\right)\left(1+\pi_{1}\right) /\left[\left(1-\varepsilon_{1}\right)(1+f)\right]}
$$

3. For $t=2, \pi_{2}$ solves

$$
\frac{E}{1-\varphi\left(\alpha, \varepsilon_{2}, \rho\right) \frac{\left(1+\pi_{2}\right)}{\left(1-\varepsilon_{2}\right)(1+f)}} \lambda\left(\alpha, \varepsilon_{1}, z_{1}, \rho, \pi_{1}, f\right)+T \frac{\left(1-\varepsilon_{2}\right)^{2} \pi_{2}}{\sigma_{2}^{2}\left(1+\pi_{2}\right)^{2}}=C^{D}\left(\pi_{2}\right)
$$

assuming $\varepsilon_{2}=\varepsilon_{0}$

\section{Data Appendix}

In Figure D.7, to construct the "Loan/GDP (Eurostat)" variable, we add "short-term bank loans to non-financial corporations" and "long-term bank loans to non-financial corporations" series from Eurostat. We compare this Eurostat variable with our own loan variable (see Table D.17 for details).

Note that in Table D.17 for "bond", "loan" and "total credit to corporations" variables, we take for the US, data from the Financial accounts of the United States. There are two reasons for this choice. Firstly, these series start in 1951 and not in 1989 as it is the case for "BIS Debt Securities Statistics". Secondly, "BIS total credit to non-financial corporations" includes in the US case both the total credit to non-financial corporations but also the credit to nonfinancial noncorporate businesses. This is not the case for European countries where BIS data includes only the credit to the corporate sector ${ }^{20}$. For comparability, we thus use US Flow of Funds data for "non-financial corporate business" (L102) in order not to include "Nonfinancial Noncorporate Business" (L.103 in US Flow of Funds).

\footnotetext{
${ }^{20}$ In contrast to the practice in the US, nonfinancial noncorporate businesses are included in many countries (in particular in Europe) in the household sector.
} 
Figure D.7 - Comparing Loans with Eurostat data
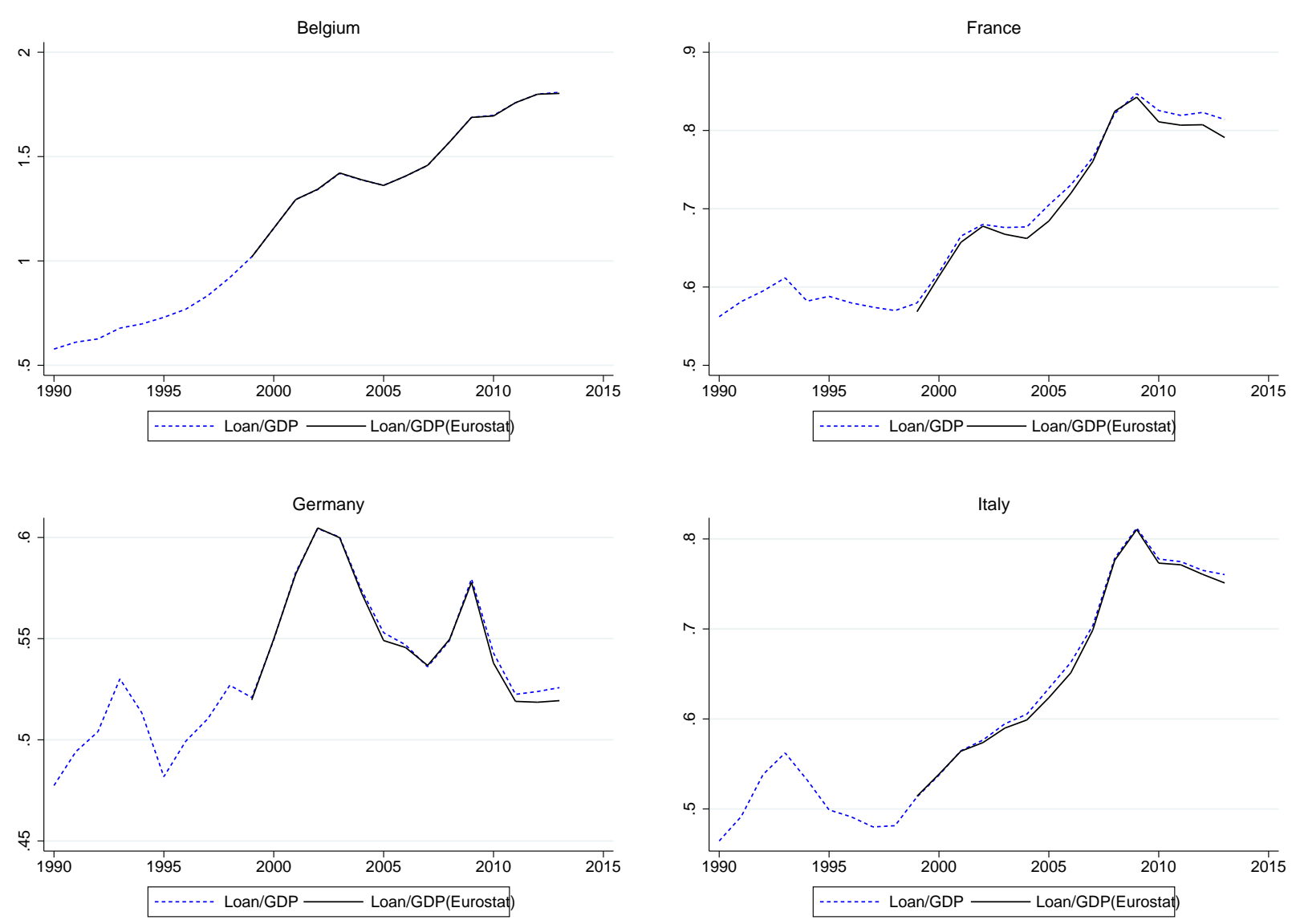


\begin{tabular}{|c|c|c|c|c|c|c|c|c|c|c|c|c|c|c|c|c|c|}
\hline 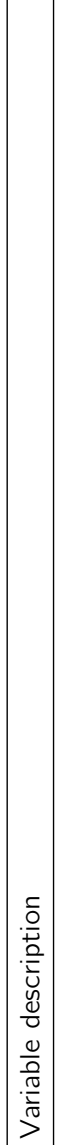 & 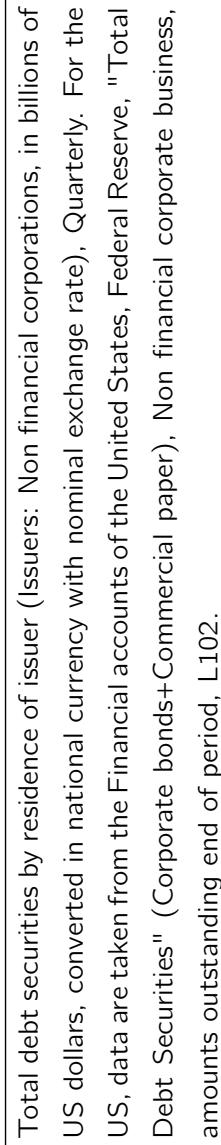 & 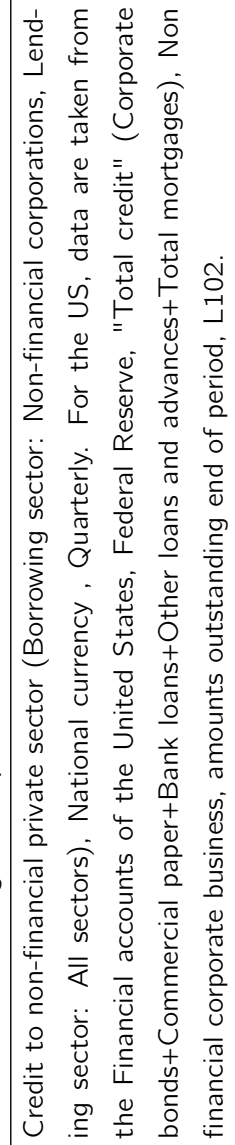 & 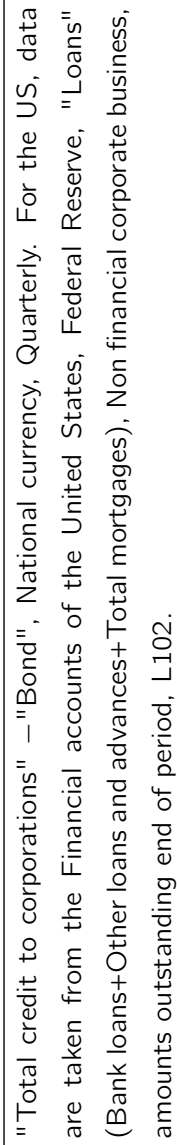 & 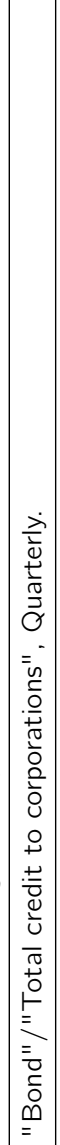 & 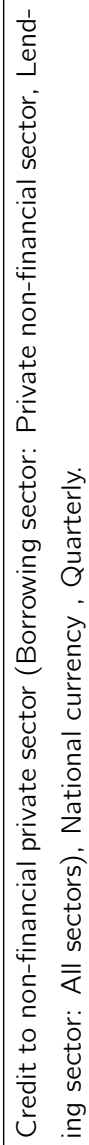 & 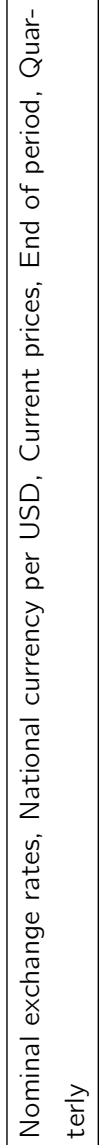 & 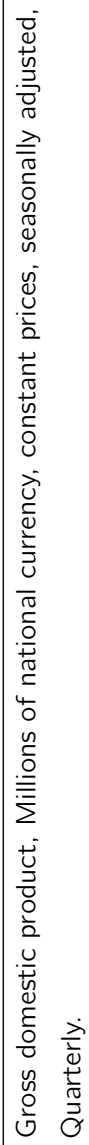 & 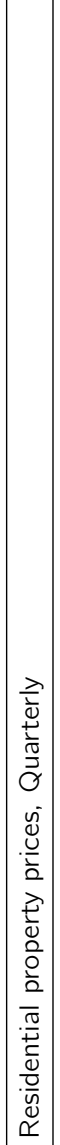 & 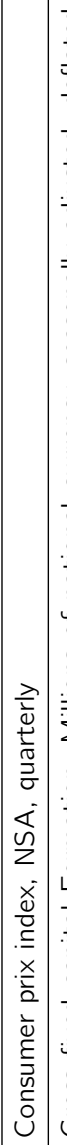 & 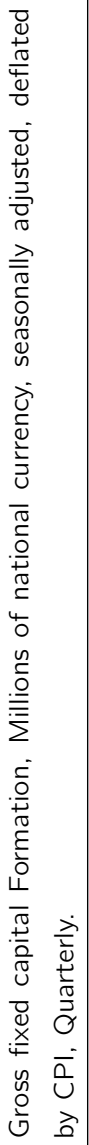 & 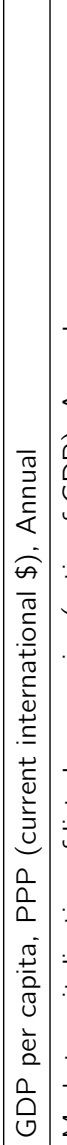 & 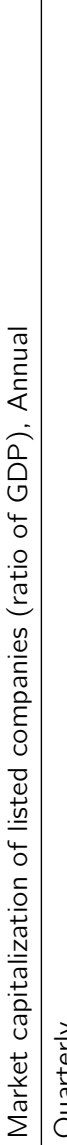 & 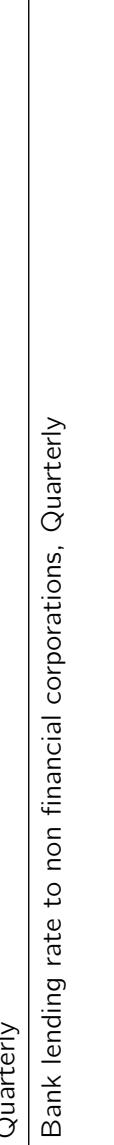 & 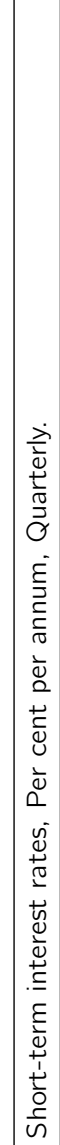 & 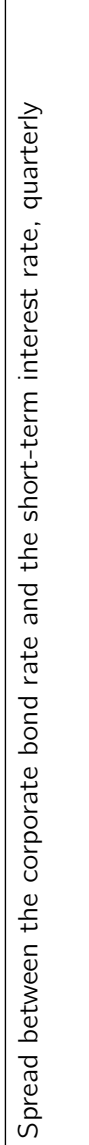 & 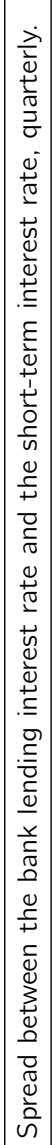 & 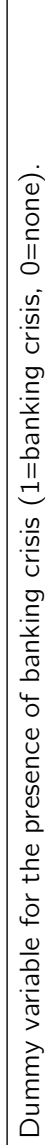 \\
\hline 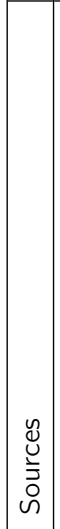 & 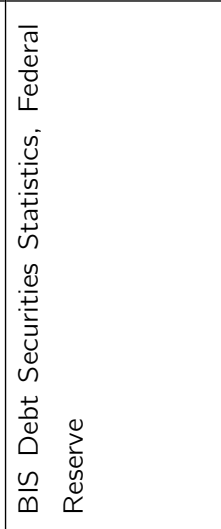 & 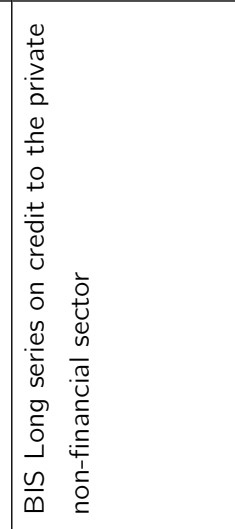 & 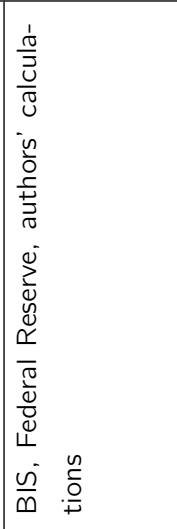 & 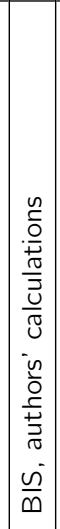 & 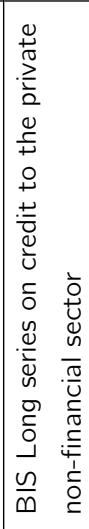 & 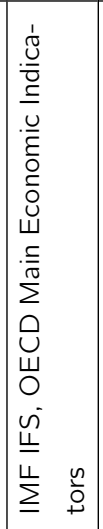 & 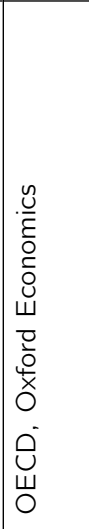 & 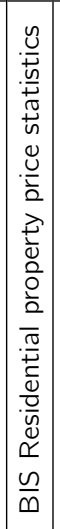 & 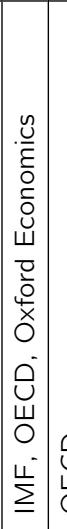 & 嵌 & 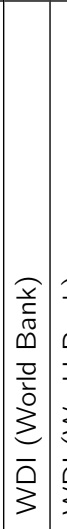 & 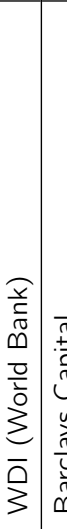 & 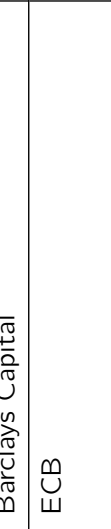 & $\begin{array}{l}\widetilde{\bar{w}} \\
\underline{\Sigma} \\
己 \\
\text { U. } \\
0\end{array}$ & 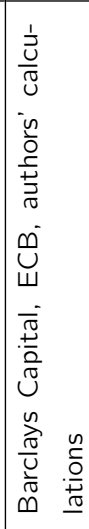 & 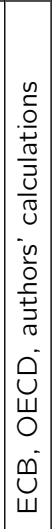 & 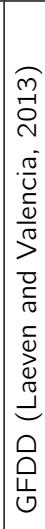 \\
\hline 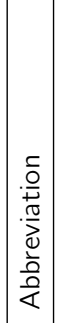 & \begin{tabular}{|l}
$\bar{z}$ \\
$\bar{z}$ \\
$\overline{0}$
\end{tabular} & 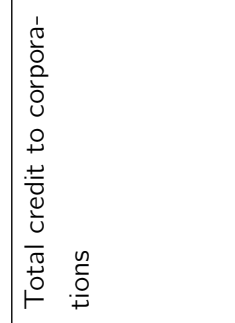 & 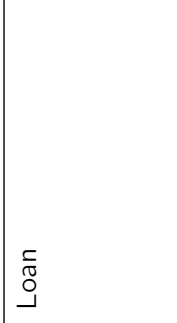 & $\mid \begin{array}{c}0 \\
\frac{0}{0} \\
\frac{D}{\omega} \\
\frac{D}{0} \\
\overline{0} \\
0\end{array}$ & 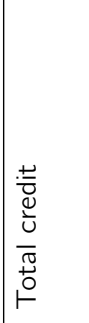 & 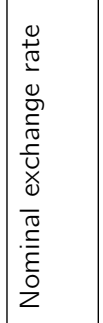 & 吕 & $\mid \begin{array}{l}\mathbf{u} \\
\stackrel{\tilde{n}}{\mathbf{0}} \\
\mathbf{I}\end{array}$ & $\overline{\mathrm{n}}$ & 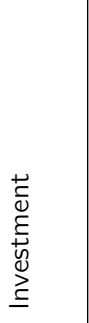 & 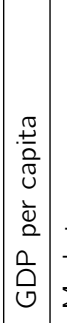 & 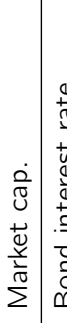 & 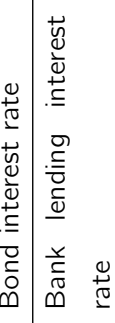 & 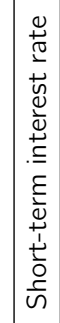 & 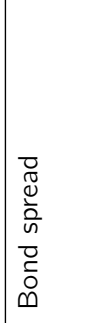 & 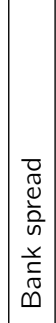 & 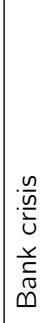 \\
\hline 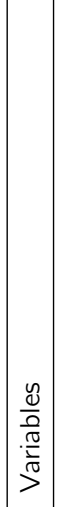 & 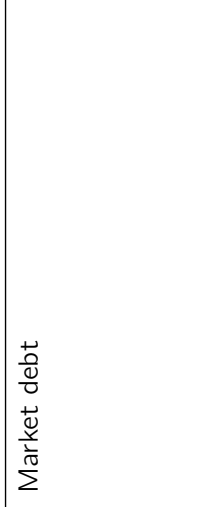 & 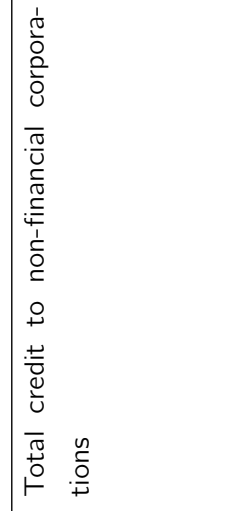 & 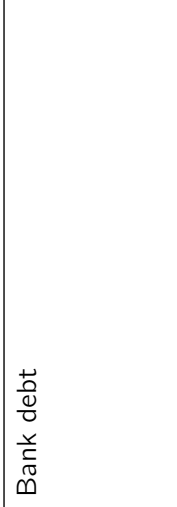 & 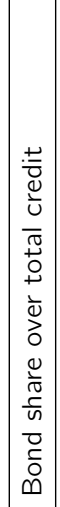 & 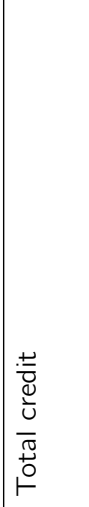 & 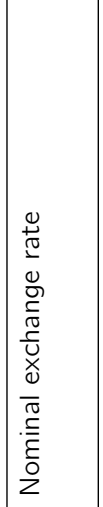 & 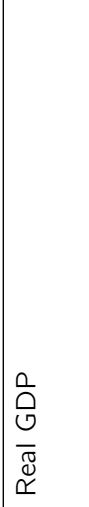 & 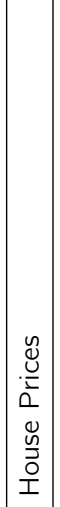 & & 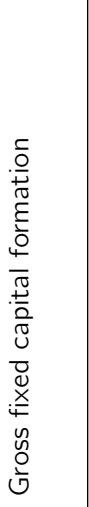 & $\begin{array}{l}0 \\
\frac{3}{2} \\
\overline{0} \\
\frac{1}{0} \\
2 \\
0 \\
0 \\
0\end{array}$ & 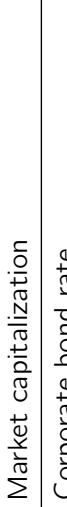 & 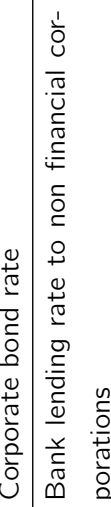 & 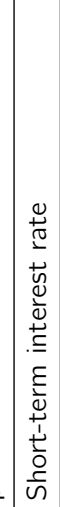 & 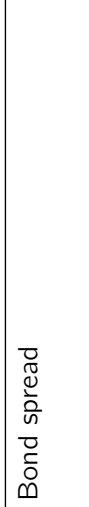 & 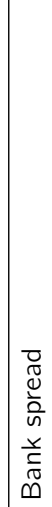 & : \\
\hline
\end{tabular}

